UCRL-ID-119231

\title{
Process Modeling of Hydrogen Production from Municipal Solid Waste
}

\author{
C. B. Thorsness
}

\author{
RECEIVED \\ NOV 171995 \\ OSTI
}

January 1995

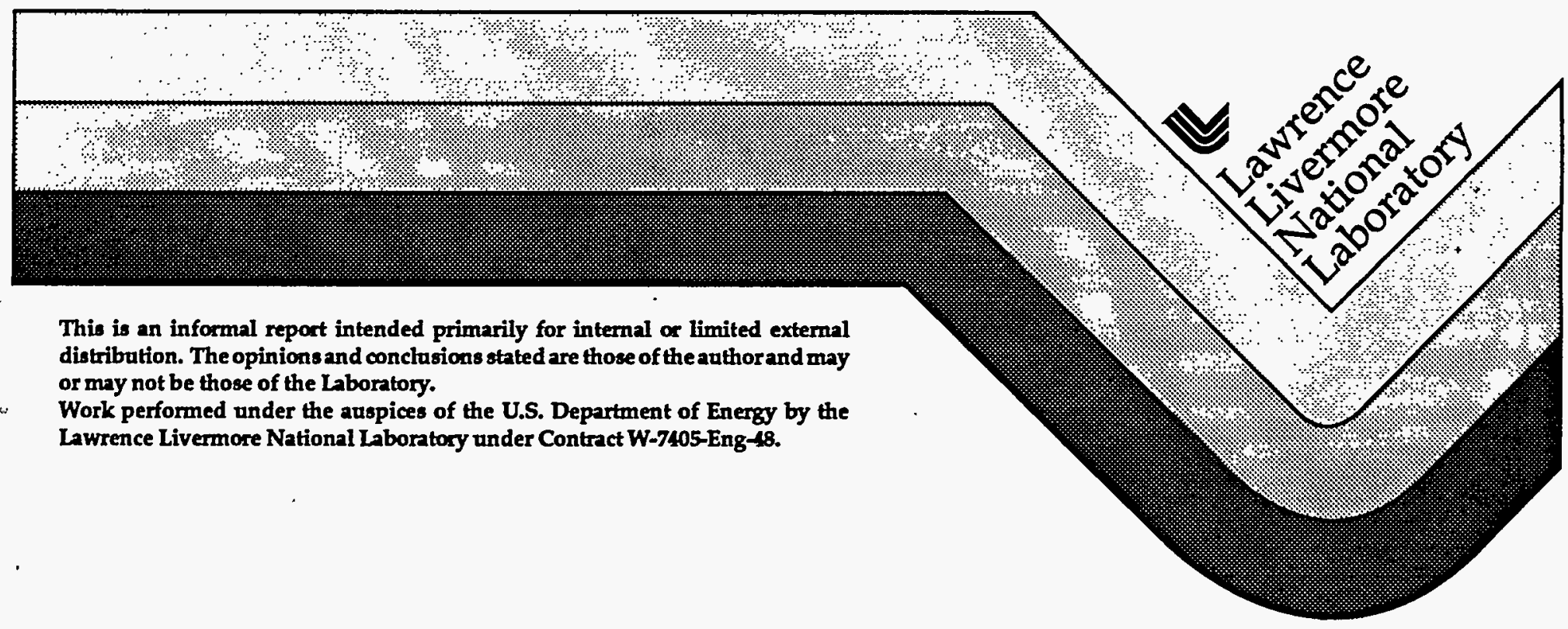

This is an informal report intended primarily for internal or limited external

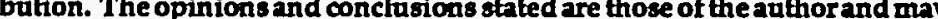

Work performed under the auspices of the U.S. Department of Energy by the Lawrence Livermore National Laboratory under Contract W-7405-Eng-\$8. 


\section{DISCLAIMER}

This document was prepared as an acccount of work sponsored by an agency of the United States Government. Neither the United States Government nor the University of California nor any of their employees, makes any warranty, express or implied, or assumes any legal liability or responsibility for the accuracy, completeness, or usefulness of any information, apparatus, product, or process disclosed, or represents that its use would not infringe privately own rights. Reference herein to any specific commercial products, process, or service by trade name, trademark, manufacturer, or otherwise, does not necessarily constitute or imply its endorsement, recommendation, or favoring by the United States Government or the University of California. The views and opinions of authors expressed herein do not necessarily state or reflect those of the United States Government or the University of California, and shall not be used for advertising or product endorsement purposes.

This report has been reproduced directly from the best available copy.

Available to DOE and DOE contractors from the Office of Scientific and Technical Information P.O. Box 62, Oak Ridge, TN 37831

Prices available from (615) 576-8401, FTS 626-8401

Available to the public from the

National Technical Information Service

U.S. Department of Commerce 5285 Port Royal Rd.,

Springfield, VA 22161 


\title{
PROCESS MODELING OF HYDROGEN PRODUCTION FROM MUNICIPAL SOLID WASTE
}

\author{
C.B. Thorsness \\ Lawrence Livermore National Laboratory \\ P.O. Box 808, L-365 \\ Livermore, CA. 94550
}





\section{TABLE OF CONTENTS}

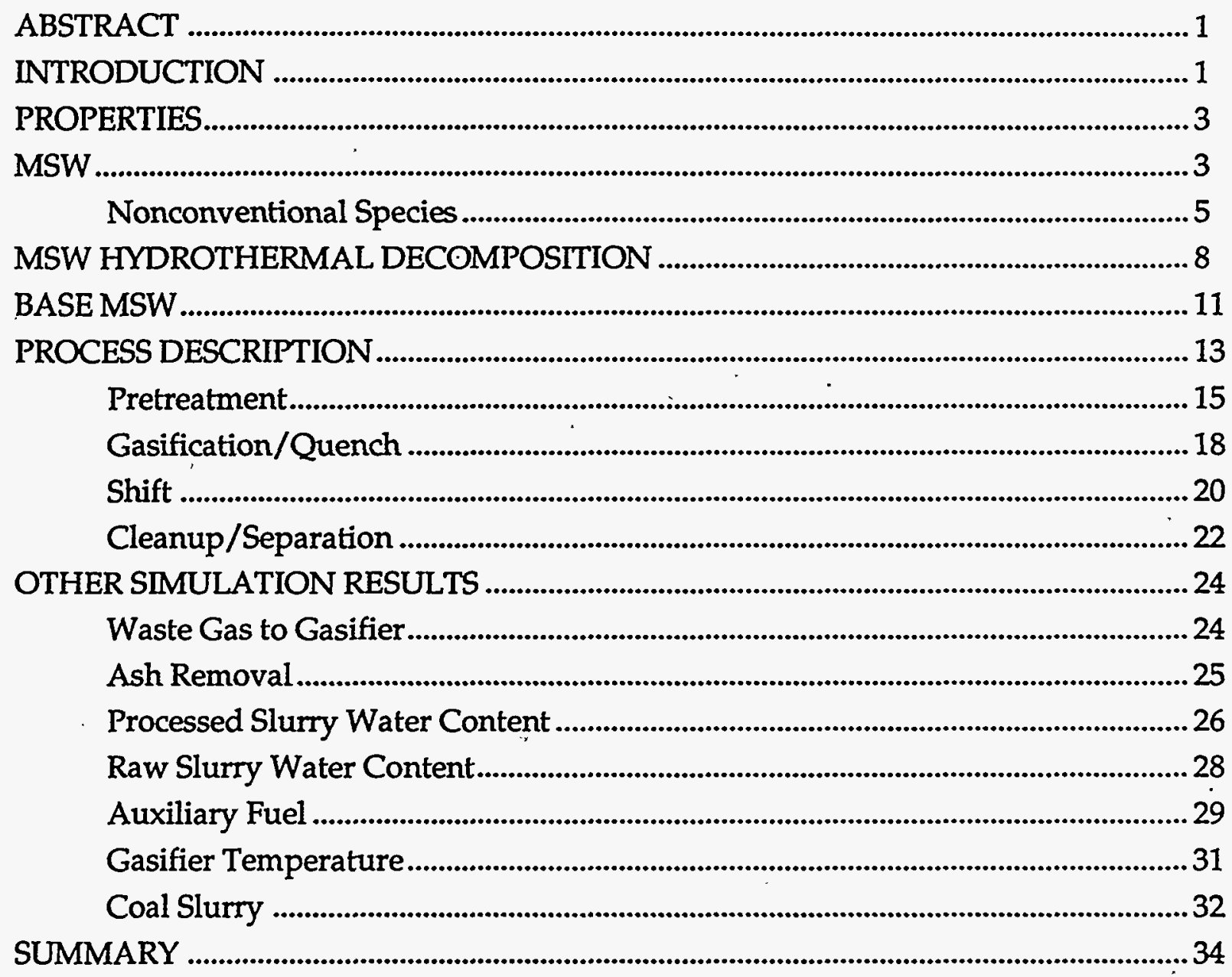





\section{ABSTRACT}

The ASPEN PLUS commercial simulation software has been used to develop a process model for a conceptual process to convert municipal solid waste (MSW) to hydrogen. The process consists of hydrothermal treatment of the MSW in water to create a slurry suitable as feedstock for an oxygen blown Texaco gasifier. A method of reducing the complicated MSW feed material to a manageable set of components is outlined along with a framework for modeling the stoichiometric changes associated with the hydrothermal treatment process. Model results indicate that $0.672 \mathrm{kmol} / \mathrm{s}$ of hydrogen can be produced from the processing of $30 \mathrm{~kg} / \mathrm{s}$ (2600 tonne/day) of raw MSW . A number of variations on the basic processing parameters are explored and indicate that there is a clear incentive to reduce the inert fraction in the processed slurry feed and that cofeeding a low value heavy oil may be economically attractive.

\section{INTRODUCTION}

This report describes a process model for gasification of municipal solid waste (MSW) to produce hydrogen. The model uses the commercial ASPEN PLUS process simulator. The motivation for development of the model was to allow physically rational estimates of important process flows involved in the production of hydrogen from MSW to be made. These estimates are being used to help guide the development of a technically and economically viable process to produce hydrogen from MSW.

MSW represents a sizable untapped resource. Approximately 200 million tons of MSW are produced in the United States annually. ${ }^{1}$ Since much of the waste consists of paper and other organic matter this waste represents a largely untapped energy source. One possibility for utilizing this resource is to apply conventional gasification technology, developed to produce synthetic fuels and power from coal, to the gasification of the organic matter in MSW. The economic motivation for considering the use of MSW as a feedstock for gasification, as opposed to coal, comes from the fact that because of the cost of developing landfill operations, a process which safely disposes of MSW can receive disposal fees, called tip or tipping fees, ranging from $\$ 25$ to $\$ 100$ per tonne. This contrasts to a cost of coal on the order of $\$ 20$ per tonne and represents a revenue source which may offset the additional feedstock treatment costs required when using MSW as a feedstock.

It is essentially impossible to introduce raw MSW to a gasification unit because of its consistency. Consequently, any gasification process requires that the MSW be modified before it is suitable for gasification. As a minimum the MSW must undergo a partial separation step and size reduction where large inert items, e.g. large pieces of concrete, are separated from the material and the size of the remaining material is reduced to a maximum size appropriate for further processing; for gasification this size is on the 
order of a few centimeters or less. At this point further processing of the raw MSW depends on the type of gasifier to be used. One attractive choice of gasifier is one which accepts wet feed, since by nature a good deal of moisture is present in the raw MSW.

One commercially viable gasification scheme which uses a wet feed is the Texaco gasifier. It has been used commercially to gasify coal, heavy oils and petroleum cokes. When this unit is run using pure oxygen as the oxidant a gasifier product composed of carbon monoxide, hydrogen, carbon dioxide and water is produced. The high temperatures developed lead to the destruction of all tars and the production of only a small amount of methane. The high temperatures also generate a fused slag containing the inorganic constituents of the feedstock in a compact environmentally benign form. The gaseous products of the Texaco gasifier are well suited to further processing to produce hydrogen, as a result of their composition and the fact that the gasifier can be run at elevated pressures well matched to downstream processing requirements.

The Texaco gasifier uses a liquid slurry feed system to introduce feedstock into a pressurized gasifier. Consequently, any feedstock must be pumpable and at the same time contain enough fuel value to allow suitably efficient operation of the unit. For slurries made of biomass derived materials, which MSW is for the most part, the fuel . value of a pumpable slurry is low. This is primarily due to the cellular structure of the solid material which leads to the sequestering of water which does not contribute to the fluidity of the slurry. For example, paper pulp slurries are pumpable up to a solids loading of no more than $10 \%$. Therefore, to make a slurry feed with solids content on the order of $50 \%$ or more, required for economic gasification something must be done to break down the physical cell structure of the MSW. In addition, biomass has relatively a lower energy value than coal because of its high oxygen content. So it is also beneficial to remove oxygen from the solid to boost its energy value per unit weight.

One means of accomplishing the required transformation of the raw MSW into a slurry suitable for gasification is to treat it hydrothermally. This involves heating the raw slurry to temperatures of $300-350 \mathrm{C}$ at pressures sufficient to maintain the water phase. At these temperatures the organic matter in biomass begins to breakdown in a process very much paralleling the formation of coal in natural settings. The cell structure is destroyed and the oxygen content is reduced by the evolution of carbon dioxide and water. It is this hydrothermal treatment which is explored in this report as a processing option for producing a suitable gasifier feedstock from MSW.

In the following sections, methods for working with the ill defined MSW within a process simulation framework are described. This leads to the definition of a typical MSW's composition and properties, along with estimates for expected transformation of the MSW during the hydrothermal treatment process. This is followed by a discussion of the process flow scheme which has been simulated and results obtained using a set of base case assumptions. Finally, comparisons to the base case results are made for a variety of changes in operating assumptions. These include a comparison to results which were computed assuming coal was used to produce the gasifier feedstock rather than MSW. 


\section{PROPERTIES}

Since the intent of the model development is to allow realistic estimates of the performance of the MSW-to-Hydrogen process to be computed, it is important that both material and energy constraints be incorporated into the simulation. The ASPEN PLUS simulator performs the required computations routinely as long as the chemical species of interest are well characterized. Many of the species needed in the simulation, like oxygen, water and hydrogen, are well defined and standard methods of computing the required thermodynamic properties are available within the ASPEN PLUS simulation environment. However, several of the important species, including MSW, are ill defined from the process simulation standpoint because they are a mixture of a large number of different constituents, and because the basic constituents themselves have no defined atomic composition or thermodynamic properties. Fortunately, ASPEN PLUS does provide a means to deal with such ill defined species through the use of what the simulator calls nonconventional solids. However, to make use of these nonconventional solids, compositional and thermodynamic properties must be defined in a way which allows ASPEN PLUS to perform the required process calculations.

In the current ASPEN PLUS simulation many of the chemical components used are conventional species. In the current simulation the following conventional species are considered: $\mathrm{H}_{2}, \mathrm{H}_{2} \mathrm{O}, \mathrm{CO}, \mathrm{CO}_{2}, \mathrm{O}_{2}, \mathrm{CH}_{4}, \mathrm{H}_{2} \mathrm{~S}, \mathrm{COS}, \mathrm{Ar}, \mathrm{Cl}_{2}, \mathrm{HCl}, \mathrm{C}$, and S.

The required atomic composition and thermodynamic properties are taken from ASPEN PLUS property models. The ASPEN PLUS property models $S Y O P 0$ and SYSOP8A have been employed.

In the remainder of this section some basic information on MSW is presented as background material. This is followed by a listing of the chemical species currently used in the ASPEN PLUS simulation and a discussion of the methods used to compute needed nonconventional species properties.

\section{MSW}

MSW is a mixture of an enormous number of individual components. The amounts of the various constituents can vary with geographical location and with time of the year. It is beyond the scope of this report to deal with this very difficult characterization process in detail, however to allow meaningful simulation of the MSW-to-Hydrogen process to be made a basic set of properties for typical MSW is required. A number of reports have dealt with composition and properties of MSW.2-5 One characterization which has been used is to break the MSW down into its constituents based on broad categories. Such a breakdown is shown in Table 1. These results come from three studies carried out from 1975 to 1994 and seem to indicate that there is some consistency in MSW makeup, at least when averages are used. Since the categories were somewhat different in each case not all entries are filled in for each study. The General Electric 
(GE) results were presented with the moisture content of the constituents broken into a separate category. Notice that in each case, waste, which is basically biomass in origin, composes a large fraction of the MSW, about 75\%. If the water for the GE study is assumed associated with biomass, the percentage for each study is remarkably consistent (within 4\%). Also notice that the paper constituent makes up half of this biomass total and is also relatively consistent from study to study. It appears that the plastic percentage has increased with time. This trend is consistent with projections made in the 1975 GE study.

Table 1. Typical MSW constituents from three sources, AICHE ' 94 ', OTA '793, and GE '75'.

\begin{tabular}{|llll|}
\hline & \multicolumn{3}{l|}{ Percentage by Weight } \\
\cline { 2 - 4 } Category & AICHE '94 & OTA'79 & GE '75 \\
\hline \hline Paper \& Paper Board & 37.5 & 32.4 & 37.0 \\
Glass & 6.7 & 10.1 & 9.0 \\
Ferrous Metal & 6.3 & 8.3 & 7.6 \\
Aluminum & 1.4 & 0.7 & \\
Nonferrous Metals & & 0.7 & 0.8 \\
Plastic & 8.3 & 3.2 & 1.4 \\
Rubber \& Leather & 2.4 & 2.6 & \\
Textiles & 2.8 & 1.5 & \\
Wood & 6.3 & 3.2 & \\
Dry Rubber, Leather, Textiles \& Wood & & & 6.0 \\
Food Waste & 6.7 & 16.8 & \\
Yard Waste & 17.9 & 19.1 & 10.0 \\
Dry Food \& Yard Waste & & & 25.0 \\
Moisture & & & 3.2 \\
Other & 3.7 & 1.4 & \\
\hline
\end{tabular}

Another useful characterization of MSW, especially from a chemical processing standpoint, is the average atomic composition and heating value. In Table 2 atomic composition and higher heating values are given for several MSW samples and other related materials. The GE ' 75 data are from the same study ${ }^{4}$ for which the constituent composition was given in Table 1 and represents an estimate made on the basis of analysis of available data. The MSW 1 and MSW 2 values are from the Biomass Handbook ${ }^{5}$ as are the newspaper and wood data (the wood is douglas fir). The other entry in the table is for RDF (refuse-derived fuel) which is partially processed MSW and is from reference 6 . Notice that on a moisture-ash-free basis the heating value and atomic ratios are fairly consistent. 
Table 2. Composition and heating value of selected MSW samples and related materials.

\begin{tabular}{|c|c|c|c|c|c|c|}
\hline & GE 75 & MSW1 & MSW 2 & Maine RDF & Newspaper & Wood \\
\hline Reference & 4 & 5 & 5 & 6 & 5 & 5 \\
\hline $\begin{array}{l}\text { Moisture (\%) } \\
\text { Ash (\%) }\end{array}$ & $\begin{array}{l}25.0 \\
22.5\end{array}$ & 12.0 & 38 & $\begin{array}{l}29.2 \\
9.5\end{array}$ & 1.5 & 0.01 \\
\hline $\begin{array}{l}\text { Moisture-ash-free solid } \\
\text { Carbon (\%) } \\
\text { Hydrogen (\%) } \\
\text { Oxygen (\%) } \\
\text { Nitrogen (\%) } \\
\text { Sultur (\%) } \\
\text { Chlorine (\%) }\end{array}$ & $\begin{array}{l}49.9 \\
6.7 \\
42.1 \\
1.1 \\
0.2 \\
0.2\end{array}$ & $\begin{array}{c}54.1 \\
6.8 \\
37.4 \\
1.4 \\
0.3\end{array}$ & $\begin{array}{c}54.7 \\
7.4 \\
36.1 \\
1.1 \\
0.6\end{array}$ & $\begin{array}{l}52.5 \\
6.9 \\
39.5 \\
0.7 \\
0.3 \\
0.2\end{array}$ & $\begin{array}{c}49.9 \\
6.2 \\
43.7 \\
0.1 \\
0.2\end{array}$ & $\begin{array}{c}50.6 \\
6.2 \\
43 \\
0.1 \\
0.02\end{array}$ \\
\hline $\begin{array}{l}\text { Atomic ratios } \\
\text { H/C } \\
\text { O/C }\end{array}$ & $\begin{array}{l}1.61 \\
0.63\end{array}$ & $\begin{array}{l}1.51 \\
0.52\end{array}$ & $\begin{array}{l}1.62 \\
0.49\end{array}$ & $\begin{array}{l}1.58 \\
0.56\end{array}$ & $\begin{array}{l}1.49 \\
0.66\end{array}$ & $\begin{array}{l}1.47 \\
0.64\end{array}$ \\
\hline Higher Heating Value (MJ/kg) & 20.8 & 22.6 & 21.2 & 22.0 & 20.0 & 20.4 \\
\hline
\end{tabular}

\section{Nonconventional Species}

To characterize the processing of the MSW in the ASPEN PLUS simulation the raw input MSW is assumed to be composed of an organic composite material characteristic of biomass derived constituents, a plastic component, an ash component and moisture or water. All but the water components are treated as nonconventional solids. At this point in the modeling process it has been assumed that the organic component and the plastic component undergo chemical change in the process while the ash passes through unchanged. In reality, the ash component would be modified, but the nature of this change would not strongly influence the overall material and energy balance of the hydrogen production process and is currently not considered.

In addition to the nonconventional solids used to specify the incoming MSW, one other nonconventional solid is defined. This solid is used to represent the solid product of the hydrothermal decomposition of the organic composite material in the MSW.

Each of the nonconventional solids has been given a component name for use in the simulation. These names are:

ORG - The composite organic material of the incoming MSW

PLS - The plastic component of the MSW

ASH - The ash component of the MSW

GORG - The solid organic product of the hydrothermal decomposition of MSW These names will be used throughout the report to designate these materials. 
To characterize these nonconventional solids, use has been made of ASPEN PLUS's built-in structures to handle coal. Often MSW, RDF and biomass are characterized using methods developed for coal when the interest is in using them as a coal substitute, as it is in this study. In order for energy balances to be performed properly, it is necessary to define enthalpies for each nonconventional solid. This requires estimates of the heats of formation and heat capacities to be made. ASPEN PLUS provides a number of ways of defining the heats of formation for coal like solids. After exploring the options, three methods have been chosen as the most convenient and accurate.

The preferred method to define heats of formation is to input the heat of combustion for a nonconventional solid. With this information, coupled with compositional information, ASPEN PLUS can compute a materials heat of formation. In those cases where heat of combustion information is not available, one of two correlations for estimating heats of composition based on compositional information has been employed. These methods require that the ash content and the $\mathrm{C}, \mathrm{H}, \mathrm{O}, \mathrm{S}, \mathrm{N} \& \mathrm{Cl}$ content of the material be available. In previous work ${ }^{7}$ it has been suggested that the ASPEN PLUS correlation based on the Boie correlation for coal most accurately predicts heats of combustion for biomass derived fuels. This correlation computes heat of combustion from weight percents of the atomic constituents and ash. Because ash appears explicitly in the basic correlation a complication arises when the material is processed and ash separates from the incoming material. As a consequence, the use of a simpler correlation based on the Dulong formula has been adopted as the best method to use when direct measurements of heat of combustion are not available.

The Dulong correlation ${ }^{8}$ is given by

$$
H_{c}=33.8 x_{c}+143.9\left(x_{H}-\frac{x_{0}}{8}\right)+9.4 x_{s}
$$

where the $x$ 's are weight fractions of $\mathrm{C}, \mathrm{H}, \mathrm{O}$ and $\mathrm{S}$ and the heat of combustion is given in units of MJ $/ \mathrm{kg}$. In Table 3 heats of combustion based on the Dulong computation and measured values are compared. Measured composition and values are from references previously sighted. In general, the Dulong correlation under estimates the heat of combustion by a few MJ $/ \mathrm{kg}$ for most of materials listed. However, the primary use of the correlation will be for intermediate materials where no heat of combustion data are available and any errors in estimating heats of formation will not effect the overall energy balance of the plant. In the future, as more information on materials of direct interest become available the default Dulong coefficients can be adjusted upward to better match the biomass related materials. 
Table 3. Measured and Dulong computed dry-ash-free heat of combustion values for selected materials.

\begin{tabular}{|c|c|c|c|c|c|c|c|c|}
\hline \multirow[b]{2}{*}{ Material } & \multirow[b]{2}{*}{ Ref. } & \multicolumn{4}{|c|}{ Dry-Ash-Free Weight \% } & \multirow{2}{*}{$\begin{array}{l}\text { Measured } \\
\text { Heat of } \\
\text { Combustion } \\
(\mathrm{MJ} / \mathrm{kg})\end{array}$} & \multirow{2}{*}{$\begin{array}{l}\text { Dulong } \\
\text { Heat of } \\
\text { Combustion } \\
(M \mathrm{M} / \mathrm{kg})\end{array}$} & \multirow{2}{*}{$\begin{array}{c}\text { Difference } \\
\text { Measured - } \\
\text { Dulong } \\
\text { (MJ/kg) }\end{array}$} \\
\hline & & C & $H$ & 0 & $\mathbf{S}$ & & & \\
\hline Brown Paper & 5 & 45.4 & 6.15 & 48.4 & 0.11 & 18.1 & 15.5 & 2.6 \\
\hline Newspaper & 5 & 49.9 & 6.19 & 43.7 & 0.16 & 20.0 & 18.0 & 2.1 \\
\hline Rice Hulls & 5 & 49.7 & 6.39 & 42.2 & 0.44 & 20.2 & 18.4 & 1.7 \\
\hline Cellulose & 5 & 44.4 & 6.18 & 49.4 & 0.00 & & 15.0 & \\
\hline Wood (douglas fir) & 5 & 50.6 & 6.18 & 43.0 & 0.02 & 20.4 & 18.3 & 2.1 \\
\hline Maine RDF & 6 & 52.5 & 6.90 & 39.5 & 0.70 & 22.0 & 20.7 & 1.3 \\
\hline GEMSW & 4 & 49.9 & 6.70 & 42.1 & 0.20 & 20.8 & 19.0 & 1.8 \\
\hline MSW 1 & 5 & 54.1 & 6.80 & 37.4 & 0.30 & 22.6 & 21.4 & 1.2 \\
\hline MSW 2 & 5 & 54.7 & 7.40 & 36.1 & 0.60 & 21.2 & 22.7 & -1.5 \\
\hline
\end{tabular}

The compositional information for these nonconventional solids are implemented through the use of ASPEN PLUS's coal related composition attributes which include proximate, ultimate and sulfur analysis. The proximate analysis is defined as the weight percent moisture, fixed carbon, volatile carbon and ash. ASPEN PLUS requires that the fixed carbon, volatile matter and ash content be given on a dry basis. In the simulation this analysis is used to compute the heat capacity of the nonconventional solids. Since this information is often not available, fixed carbon and volatile carbon values are set equal for all substances. The ultimate analysis gives the elemental composition of the material. This includes the weight percents of ash, C, H, O, N, S and $\mathrm{Cl}$. These values are given on a dry basis. The ultimate analysis is used to compute heats of combustion as needed, as described above, and to allow stoichiometric relations to be established for the nonconventional solids in various reactions occurring in the process.

The heat capacities of all nonconventional components is taken from the ASPEN PLUS default heat capacity correlation for coal like components. This is the Kirov ${ }^{9}$ correlation and uses the proximate analysis of a component to compute the heat capacity at any temperature. As used in the current model the heat capacities for nonconventional components are:

$$
\begin{aligned}
c_{p}= & x_{m}(4180)+x_{f}\left(690+2.85 T_{c}-0.00176 T_{c}^{2}\right)+ \\
& x_{v p}\left(1650+3.39 T_{c}\right)+x_{v s}\left(2970+3.39 T_{c}\right)+x_{a}\left(753+0.589 T_{c}\right)
\end{aligned}
$$

Here the heat capacity is given in $\mathrm{J} / \mathrm{kg}-\mathrm{K}, x_{a}$ is the moisture weight fraction, $x_{f}$ is fixed carbon weight fraction, $x_{v p}$ is the primary volatile matter, $x_{v s}$ is the secondary volatile matter weight fraction, $x_{a}$ is the ash weight fraction, and $T_{c}$ is the temperature in Celsius. The primary volatile matter is defined as any volatile matter in excess of $10 \%$ of the component on a dry, ash-free basis and secondary volatile matter is equal to the volatile matter content up to $10 \%$. 


\section{MSW HYDROTHERMAL DECOMPOSITION}

The decomposition of ORG (biomass related component of MSW) in the current model is handled by assuming the overall reaction can be adequately described by the following

$$
\begin{aligned}
\mathrm{CH}_{\mathrm{A}} \mathrm{O}_{\mathrm{B}}(\mathrm{ORG}) \Rightarrow & \mathrm{CH}_{2} \mathrm{O}_{\mathrm{b}}(\mathrm{GORG})+\alpha \mathrm{CO}_{2}+\beta \mathrm{CO}+ \\
& \cdot \delta \mathrm{H}_{2}+\phi \mathrm{H}_{2} \mathrm{O}+\gamma \mathrm{CH}_{4}
\end{aligned}
$$

In this overall reaction methane is used to approximate all hydrocarbon type gases produced. For simplicity, the N, $\mathrm{S}$ and $\mathrm{Cl}$ have been omitted from the simplified reaction description. Currently these species are all carried along with the GORG component.

At this time detailed data for the decomposition of typical ORG is not available, but work by Schuhmacher et al. 10 aimed at studying mechanisms of coal formation yield some information on important biomass materials. In the Schuhmacher study cellulose, lignin and wood were hydrothermally treated at a variety of temperatures and for varying times. The interest was mainly in the solid residue so that a complete stoichiometry was not reported. However, information on the residue composition, residue yield and $\mathrm{CO}_{2}$ yield were reported. This information was used, in the current study, to compute an overall reaction stoichiometry by assuming that in addition to the $\mathrm{CO}_{2}$ reported, $\mathrm{H}_{2} \mathrm{O}, \mathrm{CO}$ and $\mathrm{H}_{2}$ were also present but not reported. Including these two additional gas species allows the overall stoichiometry of the reaction to be balanced. The results are given in Table 4.

Table 4. Stoichiometric data computed from Schuhmacher et al.'s $\mathrm{s}^{10}$ hydrothermal decomposition data. The Overall entry is for the overall reaction for cellulose

\begin{tabular}{|c|c|c|c|c|c|c|c|c|c|}
\hline $\begin{array}{l}\text { Temp Time } \\
\begin{array}{ll}\text { (C) } & \text { (h) }\end{array}\end{array}$ & $\begin{array}{c}\text { GORG } \\
\mathrm{H} / \mathrm{C}\end{array}$ & $\begin{array}{c}\text { CORG } \\
\mathrm{O} / \mathrm{C}\end{array}$ & $\frac{\text { Dry G: }}{C O R}$ & $\frac{C o m s}{0}$ & $\frac{\text { ssition }}{\mathrm{H} 2}$ & $\begin{array}{r}\text { CORG } \\
\text { مORG } \\
(\mathrm{kg} / \mathrm{kg})\end{array}$ & $\begin{array}{c}\mathrm{H} 20 \\
\mathrm{ORRG} \\
(\mathrm{kg} / \mathrm{kg})\end{array}$ & $\begin{array}{c}\text { Dry Gas } \\
\text { OORG } \\
\text { (kg/kg) }\end{array}$ & $\begin{array}{c}\text { Dry Gas } \\
\text { NORG } \\
\text { (mol/kg) }\end{array}$ \\
\hline \multicolumn{10}{|c|}{ Cellulose $\mathrm{H} / \mathrm{C}=1.67 \mathrm{O} / \mathrm{C}=0.83$} \\
\hline $225 \quad 3$ & 1.27 & 0.55 & $5 \%$ & $48 \%$ & $47 \%$ & 0.55 & 0.07 & 0.38 & 23 \\
\hline 340 & 0.68 & 0.11 & $16 \%$ & $40 \%$ & $44 \%$ & 0.37 & 0.23 & 0.40 & 21 \\
\hline 340 & 0.69 & 0.09 & $33 \%$ & $28 \%$ & $39 \%$ & 0.41 & 0.28 & 0.31 & 14 \\
\hline 340 & 0.67 & 0.07 & $23 \%$ & $31 \%$ & $46 \%$ & 0.35 & 0.22 & 0.43 & 22 \\
\hline $370 \quad 3$ & 0.69 & 0.1 & $16 \%$ & $38 \%$ & $46 \%$ & 0.34 & 0.20 & 0.46 & 25 \\
\hline Overall & 0.76 & 0.1 & 1 & 0 & 0 & 0.46 & 0.33 & 0.21 & 5 \\
\hline \multicolumn{10}{|c|}{ Lignin $H / C=0.96 \quad O / C=0.36$} \\
\hline $275 \quad 3$ & 0.70 & 0.182 & $18 \%$ & $34 \%$ & $48 \%$ & 0.75 & 0.07 & 0.18 & 10 \\
\hline Wood $H / C=$ & $1.45 \mathrm{O} /$ & $\mathrm{C}=0.65$ & & & & & & & \\
\hline $340 \quad 3$ & 0.72 & 0.121 & $9 \%$ & $41 \%$ & $51 \%$ & 0.35 & 0.06 & 0.58 & 36 \\
\hline 340 & 0.63 & 0.077 & $10 \%$ & $39 \%$ & $51 \%$ & 0.35 & 0.10 & 0.54 & 33 \\
\hline
\end{tabular}
suggested by Schuhmacher et al. 
Not included in Table 4 are the results for the three cases in which at least one of the computed stoichiometric coefficients was negative. The negative coefficients indicate problems with the data or an inadequacy of the simplified reaction model. The data were also analyzed by replacing $\mathrm{H}_{2}$ with $\mathrm{CH}_{4}$ but nearly half of the cases resulted in negative stoichiometric coefficients. In their paper Schuhmacher et al. suggest that an overall reaction for cellulose would result in production of a solid residue along with $\mathrm{CO}_{2}$ and $\mathrm{H}_{2} \mathrm{O}$ (see overall entry in Table 4). This overall cellulose reaction seems to be inconsistent with the data in that more residue would be formed by such a reaction than is suggested by the data for cellulose. Notice also that in all cases the calculated dry gas composition is not consistent with the notion that $\mathrm{CO}_{2}$ is the dominate produced gas.

One way to rationalize the Schuhmacher et al. results is to assume that in addition to the insoluble residue a fairly large amount of unrecorded soluble products were produced. Computed dry gas concentrations of $\mathrm{CO}_{2}$ would increase if the soluble products of suitable stoichiometry were present. The computed $\mathrm{CO} / \mathrm{H}_{2}$ ratios, shown in Table 4, are near one. Sugars, a possible hydrolysis product of cellulose, have the generic formula $\left(\mathrm{CH}_{2} \mathrm{O}\right)_{n}$ and therefore a $\mathrm{CO} / \mathrm{H}_{2}$ ratio of one. If sugar like soluble products were formed then the stoichiometry of the reaction could be balanced with much reduced values for $\mathrm{CO}$ and $\mathrm{H} 2$ production.

For purposes of the ultimate gasification the presence of fuel as a soluble compound in the liquid phase is equivalent to fuel in the solid so that it is useful to compute a modified GORG composition from the cellulose data assuming most of the computed $\mathrm{CO}$ and $\mathrm{H}_{2}$ actually form soluble sugars and related products. Using the data from the $3 \mathrm{~h} 340 \mathrm{C}$ run the stoichiometric parameters have been computed assuming the maximum number of $\mathrm{CH}_{2} \mathrm{O}$ units are removed from the gas. The results are shown in Table 5.

Table 5. Stoichiometric results for a GORG modified to include the dissolved sugars postulated to replace produced $\mathrm{CO}$ and $\mathrm{H}_{2}$.

\begin{tabular}{|c|c|c|c|c|c|c|c|c|c|}
\hline $\begin{array}{l}\text { Temp Time } \\
\text { (C) (h) }\end{array}$ & $\begin{array}{c}\text { GOPG } \\
H / C\end{array}$ & $\begin{array}{l}\text { COFG } \\
\mathrm{O} / \mathrm{C}\end{array}$ & $\frac{\text { Dry }}{\infty}$ & $\frac{\text { as Mc }}{\infty}$ & $\frac{\%}{\mathrm{H} 2}$ & $\begin{array}{r}\text { COFG } \\
\text { ORG } \\
(\mathrm{kg} / \mathrm{kg})\end{array}$ & $\begin{array}{c}\mathrm{H} 20 \\
\text { IORG } \\
(\mathrm{kg} / \mathrm{kg})\end{array}$ & $\begin{array}{c}\text { Dry Gas } \\
\text { ORG } \\
\text { (kg/kg) }\end{array}$ & $\begin{array}{c}\text { Dry Gas } \\
\text { ORG } \\
\text { (mol/kg) }\end{array}$ \\
\hline \multicolumn{10}{|c|}{ Cellulose $\quad H / C=1.67 \quad O / C=0.83$} \\
\hline $340 \quad 3$ & 0.68 & 0.11 & $16 \%$ & $40 \%$ & $44 \%$ & 0.37 & 0.23 & 0.40 & 21 \\
\hline Modified & 1.01 & 0.33 & 78 & 0 & 22 & 0.62 & 0.23 & 0.15 & 4.3 \\
\hline
\end{tabular}

This seems to be a more reasonable view of the reaction allowing a gas dominated by $\mathrm{CO}_{2}$ to be produced but maintain atomic balances.

The heat of reaction of the decomposition reaction is also of concern since it may result in the requirement to add or remove heat during the hydrothermal processing. In general pyrolytic decomposition of organic compounds have small heats of reaction. 
Again no data is readily available, but using the Dulong formula to compute required enthalpies of formation the overall reaction represented by the modified reaction of Table 5 would have an estimated heat of reaction at $25 \mathrm{C}$ of $0.6 \mathrm{MJ} / \mathrm{kg}$ (endothermic) which is about $4 \%$ of the estimated heat of combustion of initial cellulose.

Some incomplete data on hydrothermal treatment of MSW is also available from a recent paper by Klosky et al. 11. The paper gives some results for hydrothermally treating a MSW sample at 300 and $325 \mathrm{C}$. Unfortunately, complete material balance information was not included. The reported data included relative amounts of residue, gas and water as well as approximate gas composition. Neither the composition of the feed material nor the residue was given. However, with the available information it is possible from material balance considerations to compute a residue composition for a given assumed feed composition. This has been done and the results are given in Table 6 for feed compositions (ORG) over a range which should include most if not all possible feed compositions. In all cases the results indicate that the change in hydrogen and oxygen content of the residue (GORG) is considerably less than for the biomass decomposition discussed above. These calculations were done assuming the product yield was on a moisture-free basis and that the ash content was small.

Table 6. Stoichiometric results computed from the Klosky et al. 11 data for the decomposition of MSW, ORG, into solid residue, GORG, for a variety of assumed initial MSW compositions.

\begin{tabular}{|c|c|c|c|}
\hline $\begin{array}{l}\overline{C R G} \\
H / C\end{array}$ & $\begin{array}{l}\overline{C G} \\
O / C\end{array}$ & $\begin{array}{c}\text { GORG } \\
\text { H/C }\end{array}$ & $\begin{array}{c}\text { CORG } \\
\mathrm{O} / \mathrm{C}\end{array}$ \\
\hline 1.7 & 0.8 & 1.599 & 0.590 \\
\hline 1.5 & 0.8 & 1.371 & 0.592 \\
\hline 1.3 & 0.8 & 1.152 & 0.594 \\
\hline 1.1 & 0.8 & 0.934 & 0.595 \\
\hline 1.7 & 0.6 & 1.496 & 0.401 \\
\hline 1.5 & 0.6 & 1.388 & 0.402 \\
\hline 1.3 & 0.6 & 1.178 & 0.404 \\
\hline 1.1 & 0.6 & 0.956 & 0.406 \\
\hline 1.7 & 0.4 & 1.611 & 0.215 \\
\hline 1.5 & 0.4 & 1.404 & 0.217 \\
\hline 1.3 & 0.4 & 1.191 & 0.219 \\
\hline 1.1 & 0.4 & 0.978 & 0.221 \\
\hline
\end{tabular}

Using results for an assumed MSW composition of $\mathrm{H} / \mathrm{C}=1.5$ and $\mathrm{O} / \mathrm{C}=0.6$ for the Kloskey et al. data, the heat of reaction for the decomposition is computed to be 0.5 $\mathrm{MJ} / \mathrm{kg}$. The computed heat of combustion of the produced residue would be $100 \%$ of the heat of combustion of MSW input. This last result agrees well with the Klosky et , al.'s statement that $97 \%$ of the heating value of the incoming MSW was estimated to be available in the final slurry. However, in computing the heat effects the Dulong 
formula was used for the MSW and residue. If heating values given in the Klosky et al. report are used even higher heat recovery values are computed. This discrepancy may be due to the lack of detailed information on the composition, particularly the moisture and ash content, of the MSW and the carbonized product.

\section{BASE MSW}

For the purposes of computing results in this report the following MSW feed has been assumed based on results outlined in the previous section. The base MSW is assumed to have a component composition of that given in the 1994 AIChE publication (see Table 1). From this, the MSW composition is simplified by making an initial breakdown into organic, plastic and ash fractions. These are $73.6 \%, 8.3 \%$ and $18.1 \%$ respectively. It is further assumed that the overall MSW has a moisture content of $25 \%$ and that the organic material has essentially a zero ash content. Based on these assumptions the final base component split is arrived at:

$$
\begin{aligned}
& \text { H2O - 25.0\% } \\
& \text { ORG - } 48.6 \% \\
& \text { PLS - } 8.3 \% \\
& \text { ASH - } 18.1 \% \text {. }
\end{aligned}
$$

The ORG moisture-ash-free composition is taken to be that of newspaper (Table 2) and the PLS (plastic) component is assumed to have a composition given by the General Electric work ${ }^{4}$ for average MSW plastics. This leads to an overall MSW characteristics listed in the last column of Table 7 . For the primary atomic species ( $\mathrm{C}, \mathrm{H}$ and $\mathrm{O})$ the compositional parameters fall within the range of those shown for other MSW elemental analyses. The trace component $\mathrm{Cl}$ is somewhat higher and the $\mathrm{N}$ somewhat lower. The oxygen content of the composite plastic seems high since many plastics contain little oxygen, however for now this value is used. The heat of combustion was obtained from computations using the Dulong based heat of formation estimates and is on the lower end of the MSW range. 
Table 7 Composition of MSW used in this report (column 6) compared to other MSW materials.

\begin{tabular}{|lccccc|}
\hline & GE 75 & MSW 1 & MSW 2 & Maine RDF & \begin{tabular}{c} 
Mase \\
\hline
\end{tabular} \\
\hline \hline Moisture (\%) \\
Ash (\%) & 25.0 & & & 29.2 & 25.0 \\
\hline $\begin{array}{l}\text { Moisture-ash-free solid } \\
\text { Carbon (\%) }\end{array}$ & 22.5 & 12.0 & 38 & 9.5 & 18.1 \\
Hydrogen (\%) & 49.9 & 54.1 & 54.7 & 52.5 & 51.8 \\
Oxygen (\%) & 6.7 & 6.8 & 7.4 & 6.9 & 6.6 \\
Nitrogen (\%) & 42.1 & 37.4 & 36.1 & 39.5 & 40.3 \\
Sulfur (\%) & 1.1 & 1.4 & 1.1 & 0.7 & 0.2 \\
Chlorine (\%) & 0.2 & 0.3 & 0.6 & 0.3 & 0.2 \\
Atomic ratios & 0.2 & & & 0.2 & 0.9 \\
HC & & & & & \\
O/C & 1.61 & 1.51 & 1.62 & 1.58 & 1.53 \\
Higher Heating Value (MJ/kg) & 20.8 & 22.6 & 21.2 & 22.0 & 19.8 \\
\hline
\end{tabular}

In the process modeling results it is assumed that the PLS component does not change in the hydrothermal treatment units and that the ORG component decomposes according to the stoichiometry given in Table 8 . The assumed gas composition is that taken from Klosky et al. ${ }^{11}$ and the solid product is that given in Table 5 for the modified hydrothermal products. The resulting quantities of gas, residue and water are arrived at through simple material balances. The energetics of the assumed ORG decomposition are given in the second part of the table. Notice for this choice of parameters the heat of reaction for the decomposition at $25 \mathrm{C}$ is small and all the heating value of the MSW is available in the solid product. 
Table 8. Stoichiometry and energetics used in defining MSW related components.

\begin{tabular}{|c|c|c|c|c|c|c|c|c|c|c|c|}
\hline & Food & Feed & $\begin{array}{l}\text { Solid } \\
\text { Product }\end{array}$ & $\begin{array}{l}\text { Solid } \\
\text { Product }\end{array}$ & & $y \mathbf{G a}$ & Mole & & $\begin{array}{l}\text { Solid } \\
\text { Product } \\
\text { /Feed }\end{array}$ & $\begin{array}{l}\text { H2O } \\
\text { Product } \\
\text { /Feed }\end{array}$ & $\begin{array}{l}\text { Dry Gas } \\
\text { Product } \\
\text { /Feed }\end{array}$ \\
\hline & $\mathrm{H} / \mathrm{C}$ & $\mathrm{O} / \mathrm{C}$ & $\mathrm{H} / \mathrm{C}$ & $\mathrm{O} / \mathrm{C}$ & $\infty$ & $\infty$ & $\mathrm{H} 2$ & $\mathrm{CH} 4$ & \multicolumn{2}{|c|}{$(\mathrm{kg} / \mathrm{kg})(\mathrm{kg} / \mathrm{kg})$} & $(\mathrm{kg} / \mathrm{kg})$ \\
\hline$\overline{C R G}$ & 1.49 & 0.66 & 1 & 0.33 & 80 & 4 & 7 & 9 & 0.72 & 0.19 & 0.09 \\
\hline PLS & 1.71 & 0.24 & 1.71 & 0.24 & 0 & 0 & 0 & 0 & 1 & 0 & 0 \\
\hline PAG + PLS & 1.52 & 0.60 & 1.10 & 0.32 & 80 & 4 & 7 & $\dot{9}$ & 0.76 & 0.16 & 0.08 \\
\hline
\end{tabular}

\begin{tabular}{|c|c|c|c|c|}
\hline & $\begin{array}{l}\text { Feed } \\
\text { Heating } \\
\text { Value }\end{array}$ & $\begin{array}{l}\text { Solid } \\
\text { Product } \\
\text { Heating } \\
\text { - Value } \\
\end{array}$ & $\begin{array}{c}\text { Heat } \\
\text { Reaction }\end{array}$ & $\begin{array}{l}\text { Solid } \\
\text { Product } \\
\text { / Feed } \\
\text { Heating } \\
\text { Value } \\
\end{array}$ \\
\hline & $(\mathrm{MJ} / \mathrm{kg})$ & $(\mathrm{MJ} / \mathrm{kg})$ & $(\mathrm{MJ} / \mathrm{kg})$ & \\
\hline OPG & 17.9 & 24.7 & 0.26 & 1.0 \\
\hline PLS & 30.6 & 30.6 & 0.22 & 1.0 \\
\hline $\mathrm{PRG}+\mathrm{PLS}$ & 19.8 & 25.6 & 0.25 & 1.0 \\
\hline
\end{tabular}

\section{PROCESS DESCRIPTION}

For purposes of the ASPEN PLUS simulation the overall MSW to hydrogen process has been broken up into half a dozen operational areas. These are shown schematically in Fig. 1. In the Pretreatment area hydrothermal processing is used to concentrate the fuel content of the incoming MSW resulting in a water solid slurry suitable for gasification. The slurry then moves to the Gasification area where a Texaco gasifier is used to produce raw product gas which is composed primarily of hydrogen, carbon monoxide, carbon dioxide and steam. The raw product gas next passes to the Quench area where the raw gas is quenched. This area is logically separated from the gasifier but in practice often is housed in the same physical unit as the gasification reactor. Next the gas enters the Shift area where a sulfur tolerant catalyst is used to shift the carbon monoxide to hydrogen. After shifting, the gas is cooled to drop out water and an unspecified process is used to remove the $\mathrm{H}_{2} \mathrm{~S}$. Finally, in the Separation area, the hydrogen is separated from other gases using a pressure swing adsorption operation.

A base case has been defined and computed result using the ASPEN PLUS model are also presented in Fig. 1. The base case assumes an operation at a large landfill site and the ability to produce a slurry from the MSW containing a $55 \mathrm{wt} . \%$ solids content. This solids loading is somewhat optimistic, however the assumed ash content is relatively high, $17 \mathrm{wt}$ \%, so if more inorganics can be removed in the pretreatment step, the $45 \mathrm{wt}$. $\%$ ash-free solid might be achieved. The $30 \mathrm{~kg} / \mathrm{s}$ feed rate of MSW for this base case corresponds to a daily consumption of 2600 tonnes ( $1476 \mathrm{dry}$-ash-free tonnes/day). In the schematic dashed arrows indicate energy streams, while solid arrows are mass flow 


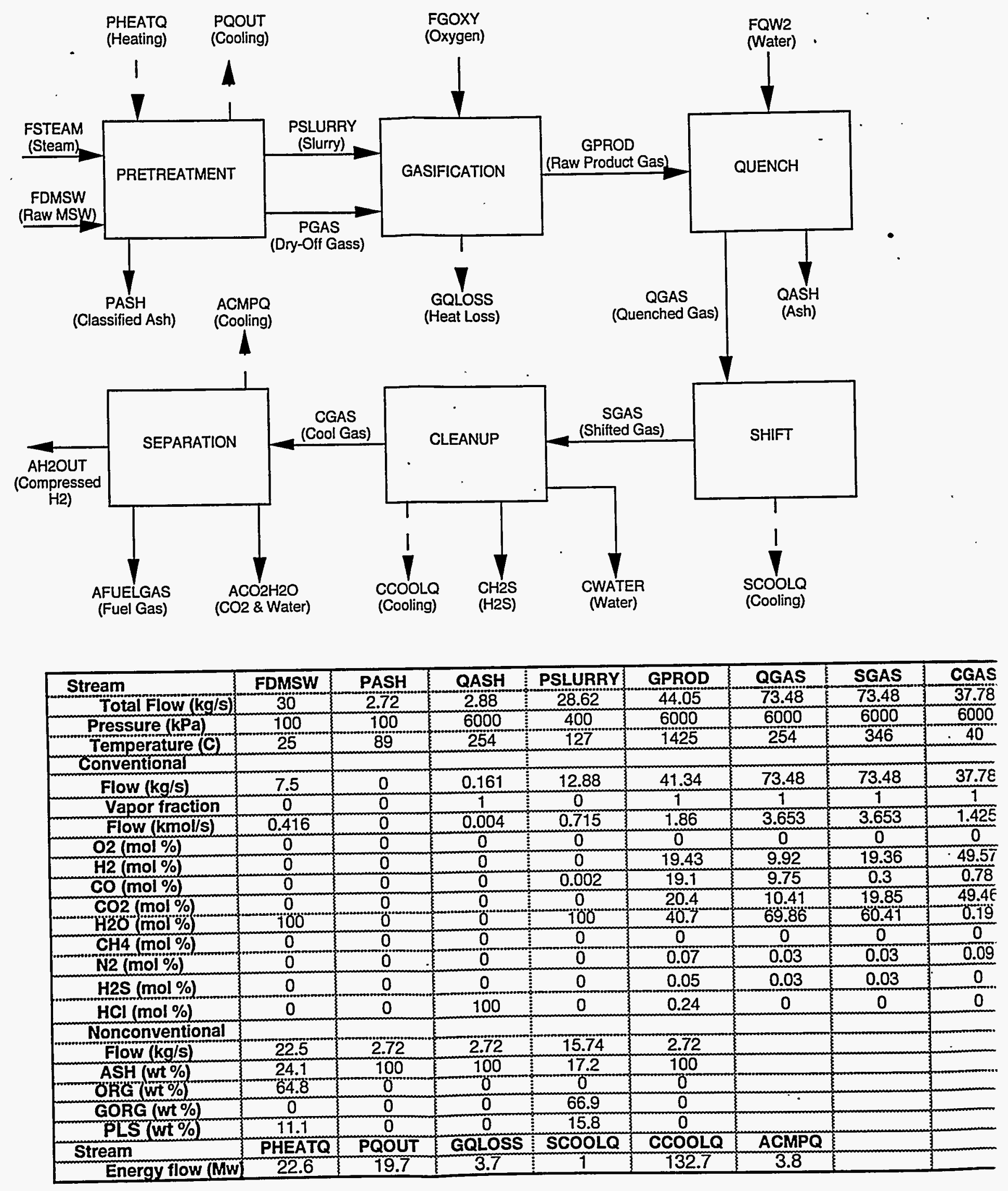

Figure 1. Overall MSW to Hydrogen conceptual process flow including all material and energy streams leaving the overall process and connecting major subprocess areas. 


\begin{tabular}{|c|c|c|c|c|c|c|c|c|c|}
\hline S & FSTEAM & FGOXY & FQW2 & CWATER & $\mathrm{CH} 2 \mathrm{~S}$ & $\mathrm{ACO} 2 \mathrm{H} 2 \mathrm{O}$ & AFUELGAS & AH2OUT & PGAS \\
\hline 8 & 2.67 & 14.1 & 32.29 & 40.7 & 0.008 & 29.15 & 2.27 & 1.36 & 1.33 \\
\hline 0 & 9763 & 8000 & 6000 & 6000 & 6000 & 130 & 130 & 6000 & 100 \\
\hline & 310 & 50 & 20 & 40 & 40 & 40 & 40 & 40 & 40 \\
\hline & & & & & & & & & \\
\hline \multirow[t]{2}{*}{8} & 2.67 & 14.1 & 32.29 & 40.7 & 0.008 & 29.15 & 2.27 & 1.36 & 1.33 \\
\hline & 1 & 1 & 0 & 0 & 0 & 1 & 1 & 1 & 1 \\
\hline \multirow[t]{2}{*}{5} & 0.148 & 0.441 & 1.793 & 2.228 & 0.0002 & 0.664 & 0.089 & 0.672 & 0.037 \\
\hline & 0 & 100 & 0 & 0 & 0 & 0 & 0 & m & سח \\
\hline \multirow[t]{2}{*}{7} & 0 & 0 & 0 & 0.04 & 0 & 0 & 38.47 & 100 & 6.5 \\
\hline & 0 & 0 & 0 & 0 & 0 & 0 & 12.42 & 0 & 3.7 \\
\hline \multirow{2}{*}{3} & 0 & 0 & 0 & 0.98 & 0 & 99.61 & 47.49 & 0 & 73.9 \\
\hline & 100 & 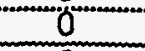 & 100 & 98.94 & 0 & 0.39 & 0.18 & 0 & 7.5 \\
\hline \multirow{2}{*}{ ram } & 0 & 0 & 0 & 0 & 0 & 0 & 0.01 & 0 & 8.4 \\
\hline & 0 & 0 & 0 & 0 & 0 & 0 & 1 & 0 & 0 \\
\hline \multirow{2}{*}{ m } & 0 & 0 & 0 & 0.03 & 100 & 0 & 0 & 0 & 0 \\
\hline & 0 & 0 & 0 & 0 & 0 & 0 & 0 & 0 & 0 \\
\hline \multirow{2}{*}{\multicolumn{10}{|c|}{$m$}} \\
\hline & & & & & & & & & \\
\hline \multicolumn{10}{|c|}{$-m$} \\
\hline \\
\hline & & & & & & & & & \\
\hline \\
\hline & & & & & & & & & \\
\hline
\end{tabular}


streams. The $30 \mathrm{~kg} / \mathrm{s}$ of raw MSW is converted to $1.36 \mathrm{~kg} / \mathrm{s}(0.672 \mathrm{kmol} / \mathrm{s})$ of hydrogen. This conversion requires $14.1 \mathrm{~kg} / \mathrm{s}(0.441 \mathrm{kmol} / \mathrm{s})$ of oxygen. In order to minimize secondary waste treatment all effluents, except separated ASH (including metals and glass), pass from the pretreatment step to the gasification. This includes the dried off gases from the hydrothermal pretreatment. Note, that the water in the MSW and that generated during pretreatment is not sufficient to supply water to the intermediate slurry product. The water deficit is made up with steam from a high pressure boiler, possibly fueled by fuel gas produced as a waste stream from the final hydrogen separation step.

The use of stream-to-stream heat exchange leads to only modest heat requirements for the process, a total of about $29 \mathrm{MW}$. The cooling requirements on the other hand are considerably greater, about $153 \mathrm{MW}$. Most of the cooling load comes from condensing water from intermediate streams. Part of the heat requirements can be obtained from the fuel gas produced as a byproduct of the process. For this base case the energy available from this stream is about $9 \mathrm{MW}$, leaving a net heat requirement for the process of $20 \mathrm{MW}$. For reference, the energy value of the produced hydrogen is $192 \mathrm{MW}$ based on the higher heating value of hydrogen $(286 \mathrm{MJ} / \mathrm{kmol})$. The energy value of the incoming MSW is $338 \mathrm{MW}$.

\section{Pretreatment}

A process flowsheet for the hydrothermal pretreatment area is shown in Fig. 2. The incoming raw MSW is mixed with recycled water and shredded. A classification by weight is then done removing some of the heavier components. An ad hoc assumption that $50 \%$ of the incoming ash will be removed in this separation has been made. This yields a material with an ash content similar to that of RDF. This initial processing . occurs at atmospheric pressure. The dilute slurry mixture is then raised to the desired reaction pressure using a high pressure pump. It then passes through a countercurrent heat exchanger system where sensible energy is recovered from reacted slurry exiting the reactor. The final reaction temperature is reached by addition of steam and indirect heating. After passing through the reactor vessel and the heat exchanger any free gas is separated from the liquid slurry. After a pressure letdown/flash, the slurry passes to a filter, or thickener, which establishes the desired solids content of the product slurry. The filtrate is then further flashed to drop the temperature so that the water can be recycled to the atmospheric operations. The flashed vapors are mixed with the separated gas and passed through a condenser. The condensate is added to the recycle stream. The recycle stream flow rate is controlled to give the desired ratio of raw MSW to water.

In this base case the final slurry product is assumed to contain $45 \%$ by weight water and has a computed higher heating value of $11.7 \mathrm{MJ} / \mathrm{kg}$. This concentration is assumed to be set by the filtering operation occurring after the pressure has been reduced to a relatively low level. One process option would involve the location within the flow 


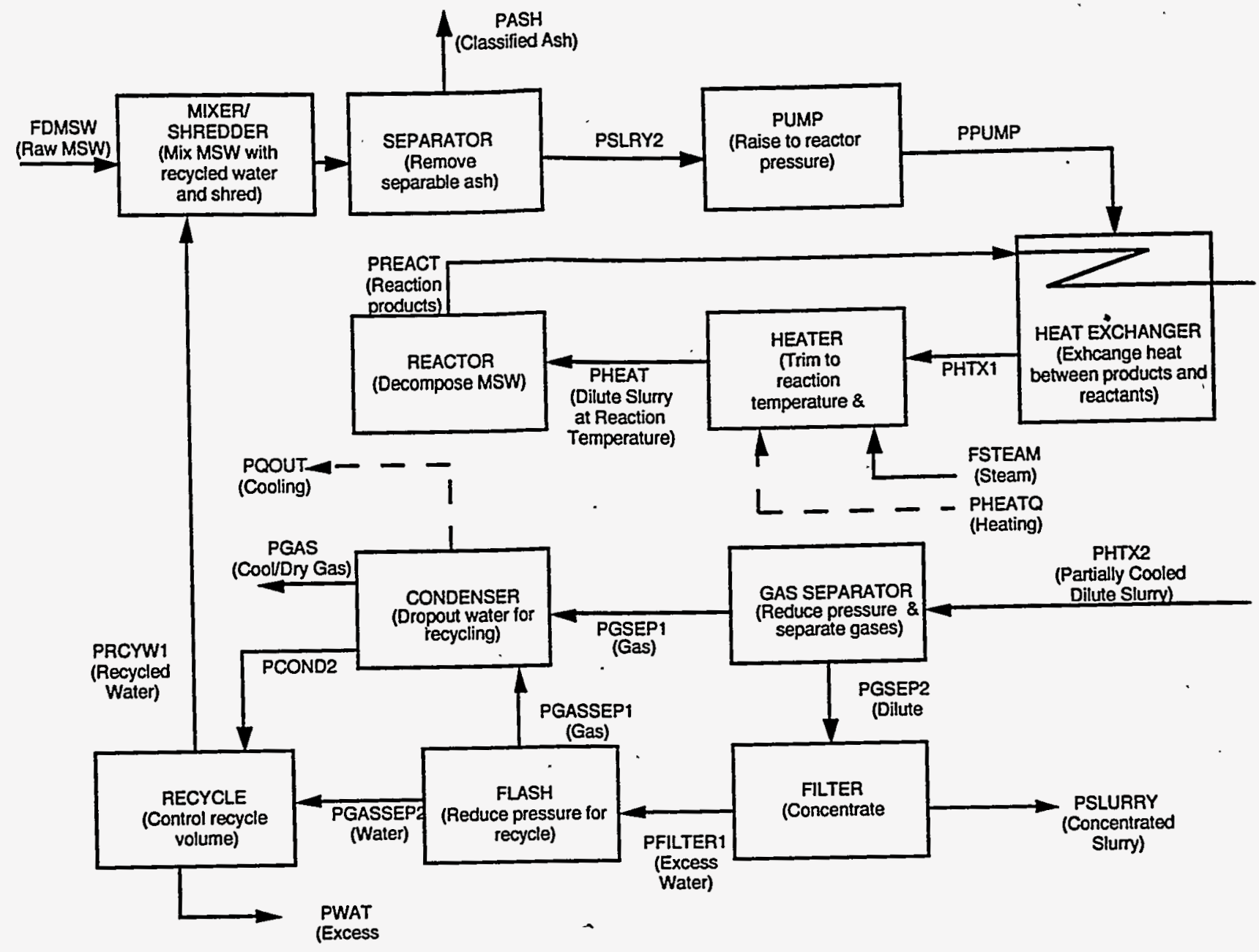

\begin{tabular}{|c|c|c|c|c|c|c|c|c|}
\hline Stream & FDMSW & FSTEAM : & PASH & PWAT & PSLURRY & PGAS & PSLRY2 & PPUMP \\
\hline Total Flow (kg/s) & (30 & 2.67 & 2.72 & 0.005 & 28.62 & 1.33 & 162.3 & 162.3 \\
\hline Pressure (kPa) & 100 & 9763 & 100 & 100 & 400 & 100 & 100 & 9000 \\
\hline Temperature (C) & 25 & 310 & 89 & 96 & 127 & 40 & 89 & 89 \\
\hline \multicolumn{9}{|l|}{$\begin{array}{l}\text { Temperature (C) } \\
\text { conventional }\end{array}$} \\
\hline Flow $(\mathrm{kg} / \mathrm{s})$ & 7.5 & 2.67 & & 0.005 & 12.88 & 1.33 & 142.5 & 142.5 \\
\hline Vapor fraction & 0 & 1 & & 0 & 0 & 1 & 0 & 0 \\
\hline Flow (kmolis) & 0.416 & 0.148 & & 0.00ั0ั03 & 0.715 & 0.037 & 7.91 & 7.91 \\
\hline $02(\mathrm{~mol} \%)$ & 0 & 0 & & ח & 0 & 0 & 0 & 0 \\
\hline $\mathrm{H} 2(\mathrm{~mol} \%)$ & 0 & 0 & & 0 & 0 & 6.5 & 0 & $\mathbf{0}$ \\
\hline CO (mol\%) & 0 & 0 & & 0 & 0.002 & 3.7 & o & o \\
\hline $\mathrm{CO} 2(\mathrm{~mol} \%)$ & 0 & 0 & & 0 & 每 & 73.9 & ena & 0 \\
\hline H2Q imelol & 100 & 100 & & 100 & 100 & 75 & 100 & 100 \\
\hline $\mathrm{CH} 4$ (mol \%) & 0 & 0 & & 0 & 0 & 8.4 & 0 & 0 \\
\hline N2 $($ mol $\%)$ & 0 & 0 & & O & سمسم & م & O & 0 \\
\hline H2S (mol \%) & 0 & 0 & 0 & 0 & 0 & 0 & 0 & 0 \\
\hline $\mathrm{HCl}(\mathrm{mol} \%)$ & 0 & 0 & 0 & 0 & 0 & 0 & 0 & 0 \\
\hline Nonconventional & & s. & & & & & & \\
\hline Flow (kg/s) & 22.5 & 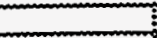 & 2.72 & & 15.74 & & 19.8 & 19.8 \\
\hline ASH $(w+\%)$ & 24.1 & 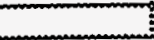 & 100 & & 17.2 & & 13.7 & 13.7 \\
\hline ORG (wt \%) & 64.8 & 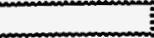 & 0 & & 0 & & 73.7 & 73.7 \\
\hline GORG (wt \%) & 0 & 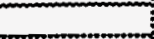 & 0 & & 66.9 & & 0 & 0 \\
\hline$p[s] w t \%)$ & 11.1 & 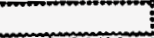 & 0 & & 15.8 & & 12.6 & 12.6 \\
\hline & PHEATQ & PQOUT & & & & & & \\
\hline Energy flow (Mw & 22.6 & 19.7 & & & & & & \\
\hline
\end{tabular}

Figure 2. The hydrothermal preprocess area showing most material and energy strear 


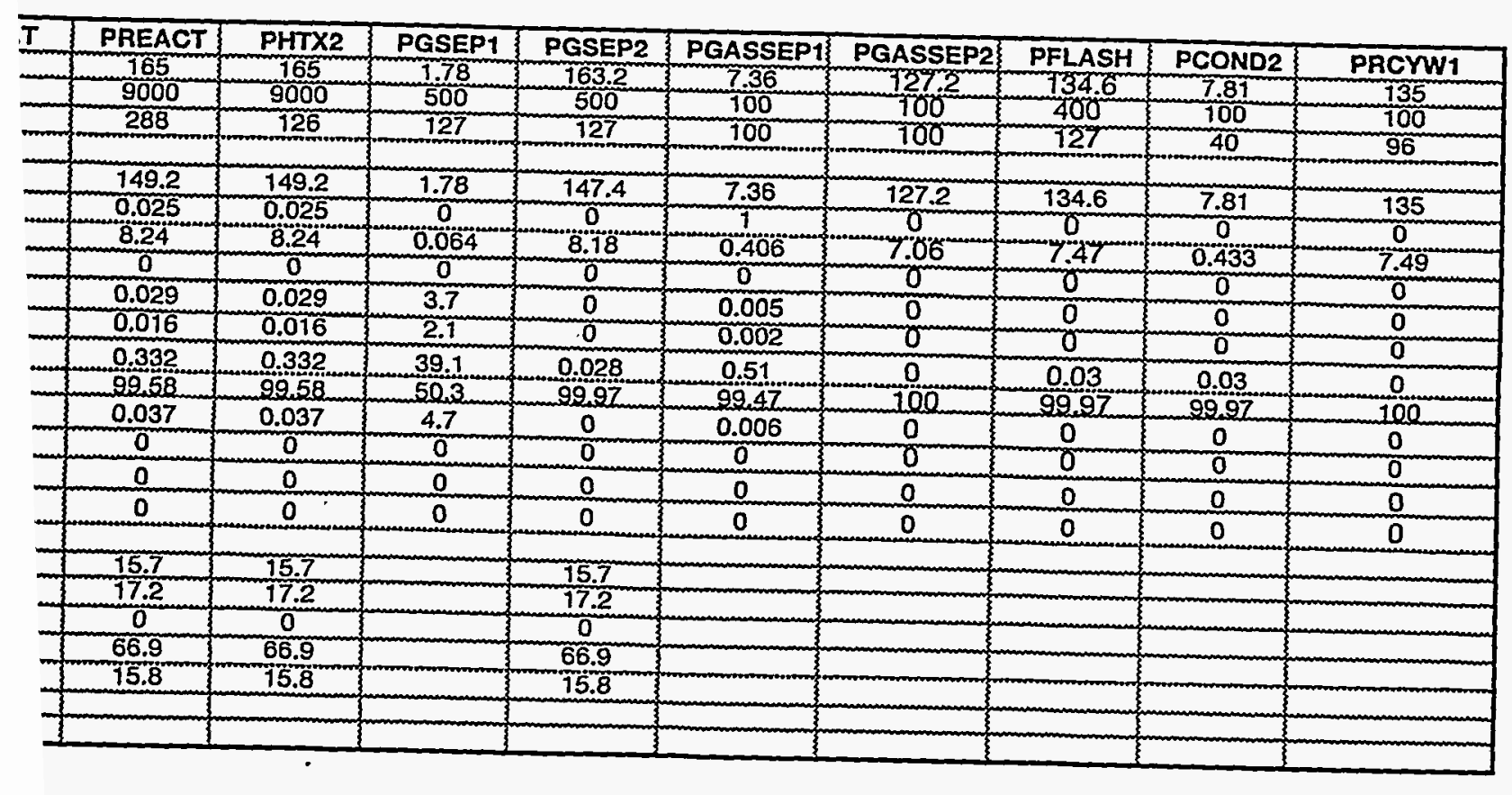


scheme of the filtering operation. If it was performed on material exiting the reactor it may help reduce fouling of heat exchanger surfaces. On the other hand, the filtering would have to be done at full system pressure. Even with the scheme shown it may be that some subcooling of the stream might have to be done to allow smooth operation of the filtering unit.

Depending on the nature and amount of ash in the stream exiting the reactor, it may be useful to add a hydroclone somewhere before the filtering operation to remove additional ash. The primary purpose of this removal step would be to increase the effective heating value of the produced slurry.

The exchange of energy between incoming and reacted slurry streams is an essential feature of the process shown. It is also subject to the greatest uncertainty because of potential plugging and fouling. In this base case $124 \mathrm{MW}$ of heat energy are exchanged between the PREACT and PPUMP streams. This represents nearly six times the $23 \mathrm{MW}$ needed to perform the final trim of the reaction temperature. The heat exchanger calculation uses an assumed overall heat transfer coefficient of $1200 \mathrm{~W} / \mathrm{m}^{2} \mathrm{~K}$ and countercurrent operation. This leads to a heat transfer surface area of $3700 \mathrm{~m}^{2}$. If an indirect transfer is required to reduce fouling this area would be larger. This exchanger size is driven by the assumed approach temperature. In this base case a $20 \mathrm{C}$ approach temperature was used. As the approach temperature is increased the exchanger area decreases but trim heat requirements increase. The choice of approach temperature and size would eventually be made on economic grounds.

All gases evolved are collected and run through a condenser in order to minimize process effluents. By condensing the water from the gas it is possible to recycle the condensate to the mixer/shredder and allow the noncondensable gases to be added to the gasifier feed. The noncondensable gas is primarily carbon dioxide and as such degrades the gasifier performance somewhat, but the gasifier is an excellent means of destroying all unwanted trace organics in the gas. In this base case, essentially all the noncondensable gas is computed to leave with the PGAS stream. The gas saturation in the liquid is done with an in built model for Henry's law constants available in ASPEN (SYSOP8A). These estimates are based on idealized models. If the amount of gas separation must be known more precisely better means of computation would probably be required, particularly for carbon dioxide which has the potential to interact with dissolved bases.

The base case shows no net water production in the Pretreatment area. The water balance is such that a slight deficit in water is present in the basic process. This deficit is made up by steam addition prior to entering the reactor. This mode of adding water assists in reaching the desired reaction temperature. In this case the steam addition represents about $30 \%$ of the water assumed to be entering the system with the MSW. Since water does leave the system with the product slurry no water purge stream is necessarily needed, however, one might be needed if buildup of some unwanted soluble product was deemed unacceptable. 
The reactor vessel would need to be $200 \mathrm{~m}^{3}$ to allow for a 15 minute residence time. This volume is about 6 times the volume of the tube side of a shell and tube heat exchanger with the necessary $3700 \mathrm{~m}^{2}$ surface area.

\section{Gasification/Quench}

A process flowsheet for the Gasification and Quench process areas is shown in Fig. 3. Operation of the gasifier is modeled after that typical of a Texaco slurry fed gasifier. This is a high temperature gasifier in which oxygen is combined with a water slurried fuel to produce a mixed gas composed of $\mathrm{H}_{2}, \mathrm{CO}, \mathrm{CO}_{2}$ and $\mathrm{H}_{2} \mathrm{O}$ and a fused slag. In addition to the slurry and oxygen feed, an auxiliary fuel stream and the PGAS are shown entering the gasifier. In the base case the flow of auxiliary fuel rate is assumed to be zero and it is assumed all the off gas from the pretreatment step is fed to the gasifier to destroy any hazardous components. The gasifier basically performs as an equilibrium reactor. For MSW slurry gasification it is assumed that the ash properties will dictate the required gasifier temperature. For the gasifier to function properly the ash must fuse and agglomerate. The desired temperature is achieved by adjusting the oxygen feed rate to the gasifier.

The gas exiting the active gasification region is assumed to be locked to a water-gasshift reaction equilibrium $375 \mathrm{~K}$ below the final reaction temperature. This approach to equilibrium seemed to best fit available data from Texaco gasifiers 7 . A small heat loss amounting to about $1-2 \%$ of the produced gas heating value is also assumed.

It is assumed, for purposes of the base case, that the hot gas exiting the active gasification zone will be quenched by passing it through a water bath. This method of quenching is the simplest and allows operation with the widest variation in ash properties. An alternate would be to use a heat recovery heat exchanger to recover useful heat energy prior to water quenching. Assuming a working temperature of 300 C. about $60-70 \mathrm{MW}$ of energy could be extracted. This is roughly twice the energy needed in the base hydrothermal pretreatment section.

In the ASPEN modeling provision was made to allow some additional shifting of carbon monoxide to hydrogen to occur as the water quench is occurring. In calculations done to date, it is assumed that the approach temperature described above has already accounted for the shifting during quench. Consequently, the water feed FQW1 has been set to zero in the base case. The ASPEN model computes the amount of water turned to steam in the quench step by assuming the gas leaves the quench with the gas stream in equilibrium with water at the final exit temperature. This temperature is of course dependent on the process pressure. In the base case an exit temperature of $254 \mathrm{C}$ is computed.

All the ash in the incoming slurry is assumed to form a solid slag in the quench operation and leave the process as a separate stream. In reality some water would be 


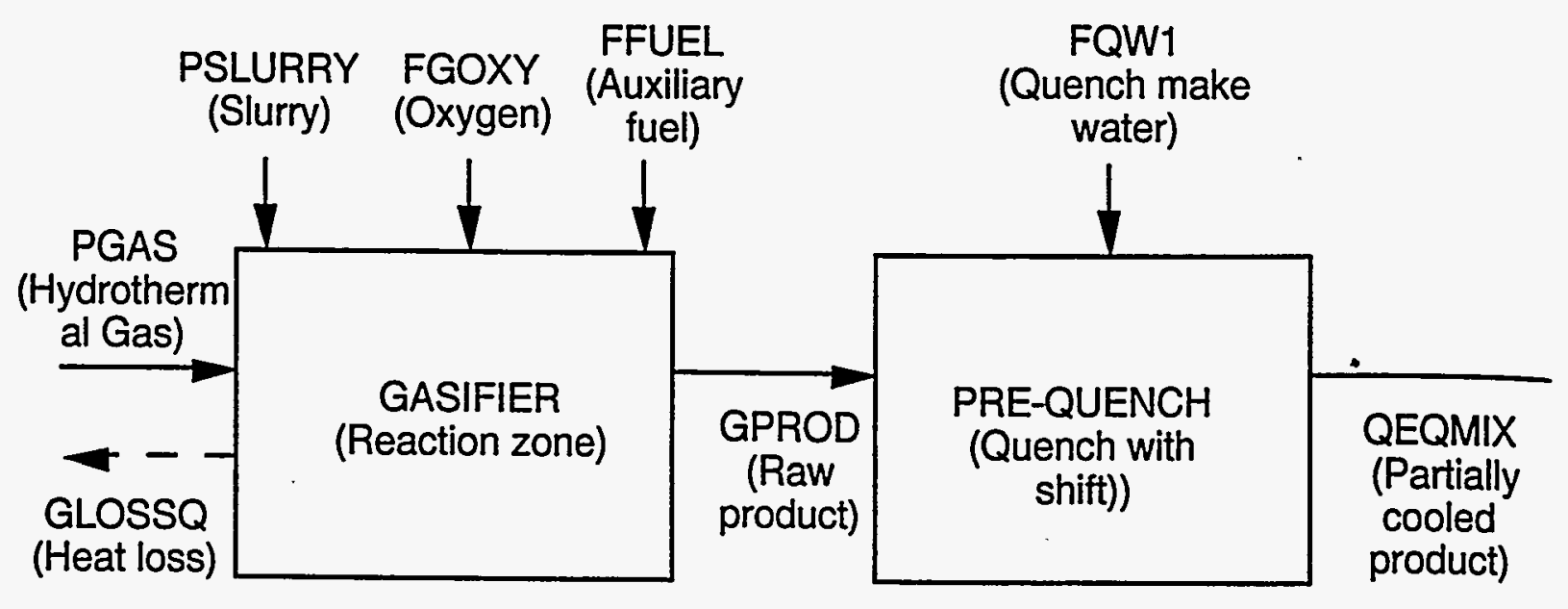

\begin{tabular}{|c|c|c|c|c|c|c|c|}
\hline Stream & PSLURRY & FGOXY & PGAS & FFUEL & FQW1 & FQW2 & QGAS \\
\hline Total Flow $(\mathrm{kg} / \mathrm{s})$ & 28.62 & 14.1 & 1.33 & 0 & 0 & 32.29 & 73.48 \\
\hline Pressure (kPa) & 400 & 8000 & 100 & 0 & 0 & 6000 & 6000 \\
\hline Temperature (C) & 127 & 50 & 40 & 0 & 0 & 20 & 254 \\
\hline \multicolumn{8}{|l|}{ Conventional } \\
\hline Flow $(\mathrm{kg} / \mathrm{s})$ & 12.88 & 14.1 & 1.33 & 0 & 0 & 32.29 & 73.48 \\
\hline Vapor fraction & 0 & 1 & 1 & 0 & 0 & 0 & 1 \\
\hline Flow (kmol/s) & 0.715 & 0.441 & 0.037 & 0 & 0 & 1.793 & 3.653 \\
\hline O2(mol\%) & 0 & 100 & 0 & 0 & 0 & 0 & 0 \\
\hline $\mathrm{H} 2(\mathrm{~mol} \%)$ & 0 & 0 & 6.5 & 0 & 0 & 0 & 9.92 \\
\hline $\mathrm{CO}(\mathrm{mol} \%)$ & 0.002 & 0 & 3.7 & 0 & 0 & 0 & 9.75 \\
\hline $\mathrm{CO} 2(\mathrm{~mol} \%)$ & 0 & 0 & 73.9 & 0 & 0 & 0 & 10.41 \\
\hline $\mathrm{H} 2 \mathrm{O}(\mathrm{mol} \%)$ & 100 & 0 & 7.5 & 0 & 0 & 100 & 69.86 \\
\hline $\mathrm{CH} 4(\mathrm{~mol} \%)$ & 0 & 0 & 8.4 & 0 & 0 & 0 & 0 \\
\hline N2 (mol \%) & 0 & 0 & 0 & 0 & 0 & 0 & 0.03 \\
\hline H2S (mol \%) & 0 & $\underline{0}$ & 0 & 0 & 0 & 0 & 0.03 \\
\hline $\mathrm{HCl}(\mathrm{mol} \%)$ & 0 & 0 & 0 & 0 & 0 & 0 & 0 \\
\hline \multicolumn{8}{|l|}{ Nonconventional } \\
\hline Flow $(\mathrm{kg} / \mathrm{s})$ & 15.74 & & & & & & 2.72 \\
\hline ASH (wt \%) & 17.2 & & & & & & 100 \\
\hline ORG (wt \%) & 0 & & & & & & 0 \\
\hline GORG (wt \%) & 66.9 & & & & & & 0 \\
\hline PLS (wt \%) & 15.8 & & & & & & 0 \\
\hline Stream & GLOSSQ & & & & & & \\
\hline Energy flow (Mw) & 3.7 & & & & & & \\
\hline
\end{tabular}

Figure 3. The gasification and quench process areas showing most material and ener! 



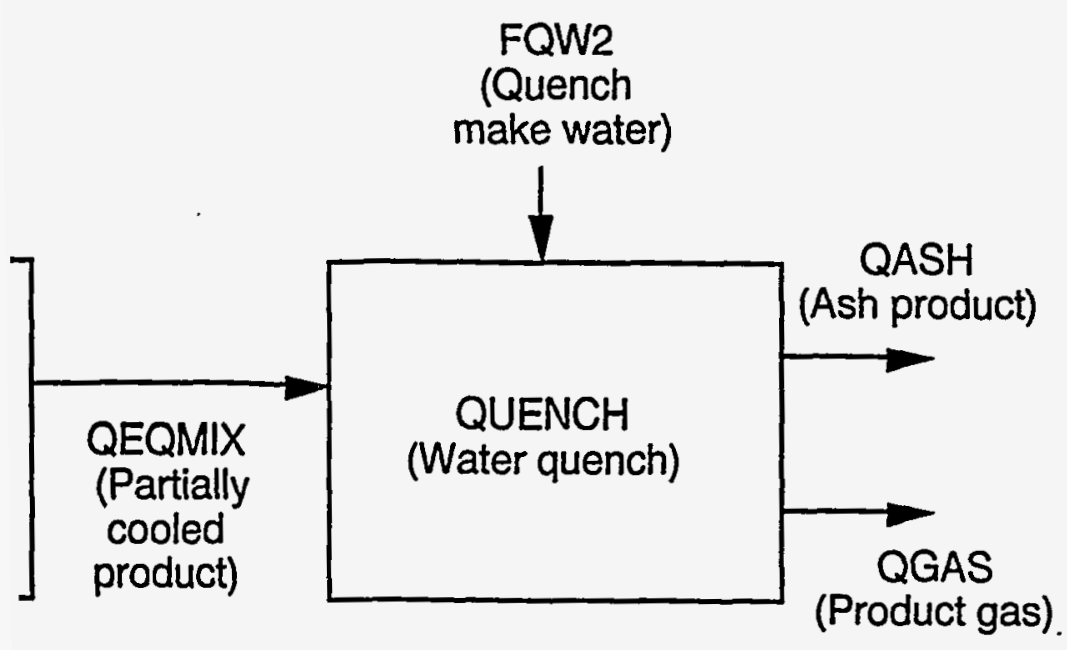

\begin{tabular}{|c|c|c|c|c|}
\hline $2 W 2$ & QGAS & QASH & GPROD & QEQMIX \\
\hline 3.29 & 73.48 & 2.88 & 44.05 & 44.05 \\
\hline 000 & 6000 & 6000 & 6000 & 6000 \\
\hline 20 & 254 & 254 & 1425 & 1425 \\
\hline .29 & 73.48 & 0.161 & 41.34 & 41.34 \\
\hline 0 & 1 & 1 & 1 & 1 \\
\hline 793 & 3.653 & 0.004 & 1.86 & 1.86 \\
\hline$\underline{0}$ & 0 & 0 & 0 & 0 \\
\hline 0 & 9.92 & 0 & 19.43 & 19.43 \\
\hline$\underline{0}$ & 9.75 & 0 & 19.1 & 19.1 \\
\hline 0 & 10.41 & 0 & 20.4 & 20.4 \\
\hline 00 & 69.86 & 0 & 40.7 & 40.7 \\
\hline 0 & 0 & 0 & 0 & 0 \\
\hline$\underline{0}$ & 0.03 & 0 & 0.07 & 0.07 \\
\hline 0 & 0.03 & 0 & 0.05 & 0.05 \\
\hline \multirow[t]{6}{*}{0} & 0 & 100 & 0.24 & 0.24 \\
\hline & 2.72 & 2.72 & 2.72 & \\
\hline & 100 & 100 & 100 & \\
\hline & 0 & 0 & 0 & \\
\hline & 0 & 0 & 0 & \\
\hline & 0 & 0 & 0 & \\
\hline & & & & \\
\hline & & & & \\
\hline
\end{tabular}

srial and energy streams. 


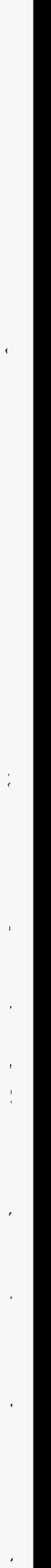


entrained in the slag and some slag carryover may occur requiring removal before further downstream processing.

\section{Shift}

In the Shift area, Fig. 4, the gas from the gasifier containing roughly equal amounts of hydrogen and carbon monoxide is shifted to produce a product with little carbon monoxide left. The carbon monoxide is converted to hydrogen through the water-gasshift reaction which is promoted by a catalyst. In the base case a sulfur tolerant catalyst is used which is effective in the temperature range of $340 \mathrm{C}$ and above.

Since there is a use for fuel gas in the process this base case uses a single catalyst type. If it is desired to maximize the production of hydrogen then a low temperature catalyst bed may be employed which is active at a lower temperature. Since the water-gas-shift reaction favors hydrogen production over carbon monoxide production at lower temperatures this, low temperature catalyst bed would shift more carbon monoxide to hydrogen. However, the low temperature catalysts are not sulfur tolerant and sulfur removal would have to occur prior to entering such a bed.

The water-gas-shift reaction is exothermic and the heat generated in the first shift reactor is assumed to be adsorbed by the gas. The heated gas exiting the reactor is used to preheat the gas coming from the gasifier quench so that the desired inlet temperature to the shift reactor, assumed here to be $340 \mathrm{C}$, is reach. About 11.6 MW of heat energy is transferred in the heat exchanger. Assuming an overall heat transfer coefficient of 250 $\mathrm{W} / \mathrm{m}^{2} \mathrm{~K}$ and countercurrent operation an exchanger area of $500 \mathrm{~m}^{2}$ is required.

Prior to entering the second stage shift reactor a small amount of cooling is done to set the temperature to $340 \mathrm{C}$. In the first shift reactor the outlet gas composition is computed assuming the exit gas is in water-gas-shift equilibrium at a temperature $25 \mathrm{C}$ above the outlet temperature. However, in the second reactor since so little reaction is occurring equilibrium at the exit temperature is assumed.

It is questionable whether a two stage shift would be required since the first stage adiabatic shift performs nearly $99 \%$ of the shifting. In reality a number of process options would be considered in optimizing the shift operation. These would include the number of shift stages, operating temperature, the need for fuel gas in the overall process, and adiabatic versus isothermal operation. The heat exchange between reactant and product gases could also be replaced by direct heating followed by heat recovery to raise steam. The details of the process would be determined by economic considerations. The scheme represented here is one simple representation of a possible process sequence. 
\begin{tabular}{|}
$\mid$ \\
$\mid$ \\
\\
\\
\\
$\mid$ \\
$\mid$
\end{tabular} 


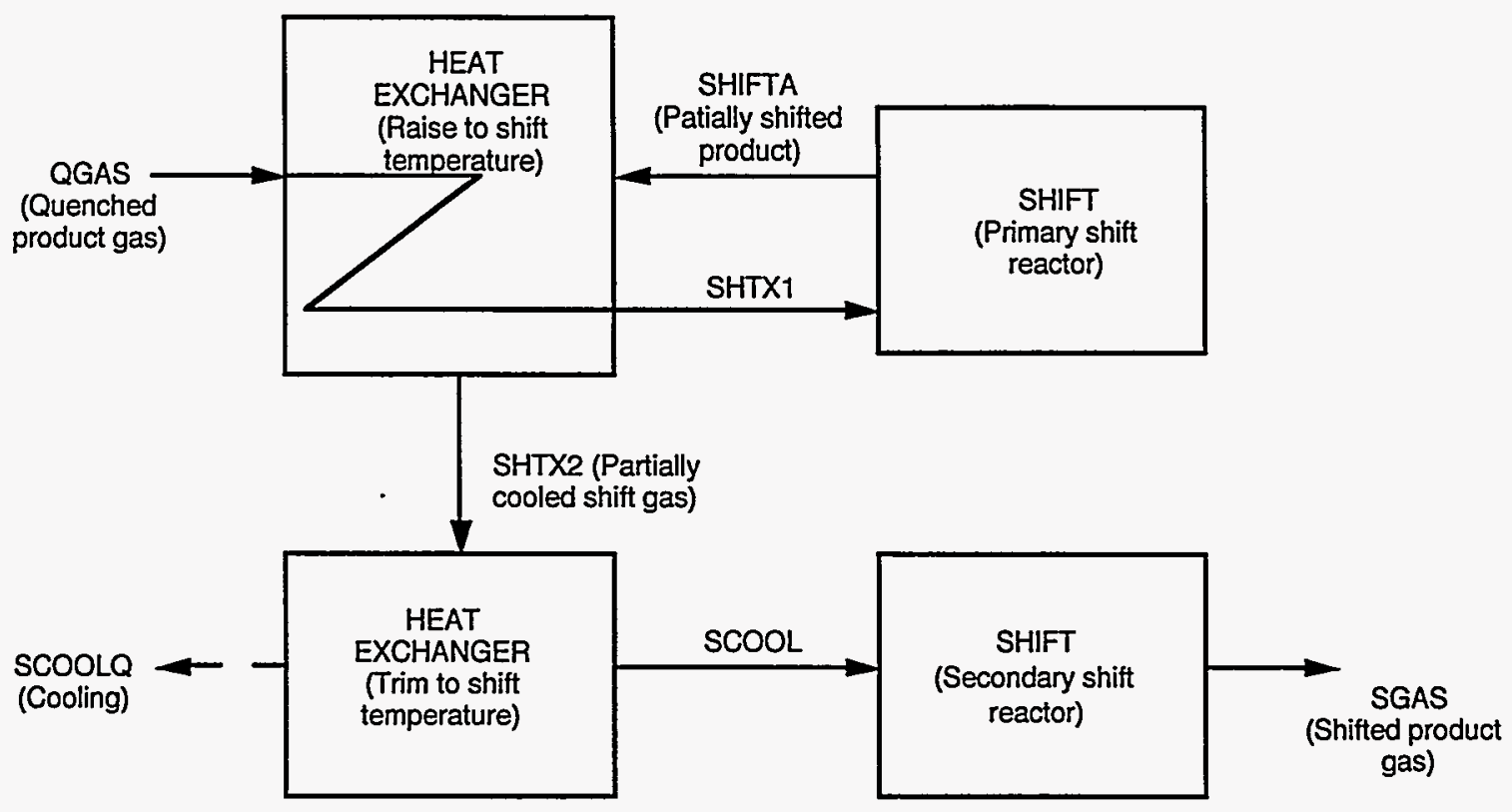

\begin{tabular}{|l|c|c|c|c|c|c|}
\hline Stream & QGAS & SGAS & SHTX1 & SHIFTA & SHTX2 & SCOOL \\
\hline Total Flow (kg/s) & 73.48 & 73.48 & 73.48 & 73.48 & 73.48 & 73.48 \\
\hline Pressure (kPa) & 6000 & 6000 & 6000 & 6000 & 6000 & 6000 \\
\hline Temperature (C) & 254 & 346 & 340 & 431 & 347 & 340 \\
\hline Conventional & & & & & & \\
\hline Flow (kg/s) & 73.48 & 73.48 & 73.48 & 73.48 & 73.48 & 73.48 \\
\hline Vapor fraction & 1 & 1 & 1 & 1 & 1 & 1 \\
\hline Flow (kmol/s) & 3.653 & 3.653 & 3.653 & 3.653 & 3.653 & 3.653 \\
\hline O2(mol \%) & 0 & 0 & 0 & 0 & 0 & 0 \\
\hline H2(mol \%) & 9.92 & 19.36 & 9.92 & 18.79 & 18.79 & 18.79 \\
\hline CO(mol \%) & 9.75 & 0.3 & 9.75 & 0.87 & 0.87 & 0.87 \\
\hline CO2 (mol \%) & 10.41 & 19.85 & 10.41 & 19.29 & 19.29 & 19.29 \\
\hline H2O(mol \%) & 69.86 & 60.41 & 69.86 & 60.98 & 60.98 & 60.98 \\
\hline CH4(mol \%) & 0 & 0 & 0 & 0 & 0 & 0 \\
\hline N2(mol \%) & 0.03 & 0.03 & 0.03 & 0.03 & 0.03 & 0.03 \\
\hline H2S (mol \%) & 0.03 & 0.03 & 0.03 & 0.03 & 0.03 & 0.03 \\
\hline HCl (mol \%) & 0 & 0 & 0 & 0 & 0 & 0 \\
\hline Stream & SCOOLQ & & & & & \\
\hline Energy flow (Mw) & 1 & & & & & \\
\hline
\end{tabular}

Figure 4. The shift process area showing most material and energy streams. 


\section{Cleanup/Separation}

Fig. 5 shows a flowsheet schematic of unit operations assumed to occur in the Cleanup and Separation areas. The cleanup is assumed to involve removal of hydrogen sulfide and water from the product stream. In the ASPEN model the water is removed by condensation and the hydrogen sulfide is separated using some unspecified process. Depending on the amount of hydrogen sulfide and the tolerance of PSA beds a specific process would need to be selected which minimized overall costs.

The water is assumed to leave the hydrogen sulfide separation unit at $40 \mathrm{C}$. The hydrogen sulfide is assumed to be totally removed, while the amount of water condensed and the amount of dissolved gases are obtained from equilibrium considerations. The condensed water would supply all the water needed for the gasifier gas quench and for steam production for injection in the pretreatment step.

The dissolved gases in stream CWATER are computed using built-in Henry's Law correlations for the gases. The effective Henry's Law constants computed by ASPEN PLUS (SYSOP8A option) at $40 \mathrm{C}$ are fairly good. Compared to values reported in recent work ${ }^{12}$ on nonpolar species, the values of Henry's Law constants computed at $40 \mathrm{C}$ by ASPEN PLUS for nitrogen are almost right on, the value for hydrogen is about $10 \%$ low and the value for methane is about $25 \%$ high. For carbon dioxide the value of the Henry's Law constant computed by ASPEN PLUS at $40 \mathrm{C}$ is $45 \%$ higher than that reported by Chen et al: ${ }^{13}$ for this polar molecule which comprises the bulk of the gas (stream excluded). At higher temperatures the ASPEN PLUS estimates for Henry's Law constants of all gas components seems to be high (see Appendix A for more details). However, the amount of dissolved gases computed by ASPEN PLUS, based on these constants, is a very small fraction of the total for all species except carbon dioxide. For all non-carbon dioxide species the ratio of dissolved species to gas phase species is less than 0.002 to 1 . For carbon dioxide it is 0.031 to 1 . If the amount of carbon dioxide in the condensed water becomes an important consideration an improved model for the Henry's Law constant for this species would be needed. The relation would also have to take into account the $\mathrm{pH}$ and other chemistry of the water at this point in the process.

The final hydrogen product is assumed to be separated from other gases using a three bed PSA operation. The efficiency of each bed was estimated from data from a report by Sircar ${ }^{14}$. Although the PSA operation is shown here as three beds operating continuously, the actual PSA operation involves a series of beds which are sequenced through pressurization and depressurization cycles.

Besides the desired hydrogen product a fuel gas stream is produced. The estimated heat energy available in the fuel gas is approximately $9 \mathrm{MW}$. This is about $40 \%$ of the heat energy needed in the pretreatment process. In a final design it may be that it is more economical to use smaller PSA beds which are less efficient and thus yield more fuel gas since the fuel gas can be effectively used within the process. 


\begin{tabular}{|c|c|c|c|c|c|c|c|c|}
\hline & \multicolumn{2}{|c|}{$\begin{array}{l}\text { CCOOLQ } \\
\text { (Cooling) }\end{array}$} & & & $\overbrace{(\mathrm{H} 2 \mathrm{~S})}^{\mathrm{CH} 2 \mathrm{~S}}$ & & & \\
\hline $\begin{array}{l}\text { SGAS } \\
\text { (Product gas from } \\
\text { shift) }\end{array}$ & \multicolumn{2}{|c|}{ CONDENSOR } & & \multicolumn{2}{|c|}{ H2S SEPARATION } & \multicolumn{3}{|c|}{$\begin{array}{c}\text { - CWATER } \\
\text { (Water) }\end{array}$} \\
\hline $\begin{array}{c}\text { AH2OUT } \\
\text { (Compressed H2 } \\
\text { product) } \\
\substack{\text { APSA-B2 } \\
\text { (High }}\end{array}$ & \multicolumn{2}{|c|}{$\begin{array}{l}\text { PSA STAGE-B } \\
\text { (CH4, CO, N2 \& } \\
\text { CO2 adsorbed) }\end{array}$} & APSA-A2 & \multicolumn{2}{|c|}{$\begin{array}{r}\text { CGAS (C } \\
\text { fre }\end{array}$} & $\begin{array}{l}\text { Cool H2S- } \\
\text { free } \\
7\end{array}$ & $\begin{array}{l}\mathrm{CO} 2 \mathrm{H} 2 \mathrm{O} \\
2 \mathrm{O} \& \mathrm{CO} 2 \\
\text { gases) }\end{array}$ & - \\
\hline $\begin{array}{l}\text { APSA-C1 } \\
\text { (High } \\
\text { pressure H2) }\end{array}$ & \multicolumn{2}{|c|}{$\begin{array}{l}\text { PSA STAGE-C } \\
\text { (CH4, CO \& CO2 } \\
\text { adsorbed) }\end{array}$} & & \multicolumn{2}{|c|}{$\begin{array}{c}\text { COMPRESSOR } \\
\text { (Recompress } \\
\text { product stream) }\end{array}$} & \multicolumn{2}{|c|}{$--\begin{array}{l}\text { ACMPQ } \\
\text { (Cooling) }\end{array}$} & \\
\hline Stream & SGAS & $\mathrm{CH} 2 \mathrm{~S}$ & CWATER & $\mathrm{ACO} 2 \mathrm{H} 2 \mathrm{O}$ & AFUELGAS & AH2OUT & CGAS & APSA-A2 \\
\hline Total Flow $(\mathrm{kg} / \mathrm{s})$ & 73.48 & 0.008 & 40.7 & 29.15 & 2.27 & 1.36 & 37.78 & 3.63 \\
\hline Pressure $(\mathrm{kPa})$ & 6000 & 6000 & 6000 & 130 & 130 & 6000 & 6000 & 6000 \\
\hline Temperature (C) & 346 & 40 & 40 & 40 & 40 & 40 & 40 & 40 \\
\hline Conventional & & & & & & & & \\
\hline Flow $(\mathrm{kg} / \mathrm{s})$ & 73.48 & 0.008 & 40.7 & 29.15 & 2.27 & 1.36 & 37.78 & 7.26 \\
\hline Vapor fraction & 1 & 0 & 0 & 1 & 1 & 1 & 1 & 1 \\
\hline Flow (kmol/s) & 3.653 & 0.0002 & 2.228 & 0.664 & 0.089 & 0.672 & 1.425 & 0.761 \\
\hline O2(mol \%) & 0 & 0 & 0 & 0 & 0 & 0 & 0 & 0 \\
\hline $\mathrm{H} 2(\mathrm{~mol} \%)$ & 19.36 & 0 & 0.04 & 0 & 38.47 & 100 & 49.57 & 92.81 \\
\hline $\mathrm{CO}(\mathrm{mol} \%)$ & 0.3 & 0 & 0 & 0 & 12.42 & 0 & 0.78 & 1.45 \\
\hline $\mathrm{Co2}(\mathrm{mol} \%)$ & 19.85 & 0 & 0.98 & 99.61 & 47.49 & 0 & 49.46 & 5.55 \\
\hline $\mathrm{H} 2 \mathrm{O}(\mathrm{mol} \%)$ & 60.41 & 0 & 98.94 & 0.39 & 0.18 & 0 & 0.19 & 0.02 \\
\hline $\mathrm{CH} 4(\mathrm{~mol} \%)$ & 0 & 0 & 0 & 0 & 0.01 & 0 & 0 & 0 \\
\hline N2 $(\mathrm{mol} \%)$ & 0.03 & 0 & 0 & 0 & 1 & 0 & 0.09 & 0.16 \\
\hline H2S (mol \%) & 0.03 & 100 & 0.03 & 0 & 0 & 0 & 0 & 0 \\
\hline $\mathrm{HCl}(\mathrm{mol} \%)$ & 0 & 0 & 0 & 0 & 0 & 0 & 0 & 0 \\
\hline Stream & CCOOLQ & ACMPQ & & & & & & \\
\hline Energy flow (Mw) & 132.7 & 3.8 & & & & & & \\
\hline
\end{tabular}

Figure 5. The pressure swing adsorption (PSA) process area showing most material and energy strear 



\begin{tabular}{|c|c|c|c|}
\hline IPSA-A2 & APSA-B1 & APSA-B2 & APSA-C1 \\
\hline 3.63 & 2.52 & 1.11 & 0.24 \\
\hline 6000 & 130 & 6000 & 6000 \\
\hline 40 & 40 & 40 & 40 \\
\hline 7.26 & 2.52 & 1.11 & 0.24 \\
\hline 1 & 1 & 1 & 1 \\
\hline 0.761 & 0.21 & 0.551 & 0.121 \\
\hline 0 & 0 & 0 & 0 \\
\hline 92.81 & 73.97 & 100 & 100 \\
\hline 1.45 & 5.26 & 0 & 0 \\
\hline 5.55 & 20.09 & 0 & 0 \\
\hline 0.02 & 0.08 & 0 & 0 \\
\hline 0 & 0 & 0 & 0 \\
\hline 0.16 & 0.59 & 0 & 0 \\
\hline 0 & 0 & 0 & 0 \\
\hline 0 & 0 & 0 & 0 \\
\hline & & & \\
\hline & & & \\
\hline
\end{tabular}

'gy streams. 

In the computations it is assumed that the final desired delivery pressure of the hydrogen is $6000 \mathrm{kPa}$, which is the same pressure as the gasifier. If a different final pressure is desired more or less compression can be used in the PSA step, however it may be most economical to change the operating pressure of the entire plant. Gasification reactors have been operated at a pressures as high as $8000 \mathrm{kPa}$.

\section{OTHER SIMULATION RESULTS}

In addition to calculations for the base case, a number of other cases have been computed. These cases include variations in waste gas flow to the gasifier, in amount of ash removal, in water content of the final gasifier feedstock, in amount of auxiliary feedstock input to the gasifier, in solid content of the raw slurry feed to the hydrothermal treatment units and in gasifier temperature. In this section selected results are presented for these variations in operating conditions. In each MSW case the input rate of raw MSW has been held constant at $30 \mathrm{~kg} / \mathrm{s}$. In addition calculations are presented for a coal/water slurry gasifier feed to allow comparisons to be made to MSW slurry operations.

\section{Waste Gas to Gasifier}

In the base case it assumed that waste gas produced from the hydrothermal treatment is injected into the gasifier. This operation has the advantage of using the gasifier as a means of destroying any hazardous components in the gas stream and leaving only unheated ash and the slurry feedstock as process streams exiting the hydrothermal units. However, since this gas is composed primarily of carbon dioxide it has the potential to degrade the performance of the gasifier. To look at the influence of this gas a model run was done in which the PGAS stream was not fed to the gasifier.

Primarily because the flow rate of the waste gas stream, PGAS, is small, $1.33 \mathrm{~kg} / \mathrm{s}$, compared to the slurry flow rate of $28.6 \mathrm{~kg} / \mathrm{s}$, the computed degradation in process performance is relatively minor. The amount of hydrogen produced is essentially unchanged, see Table 9, while the amount of oxygen required by the gasifier increases slightly. Energy flows into and out of the system remain essentially unchanged. 


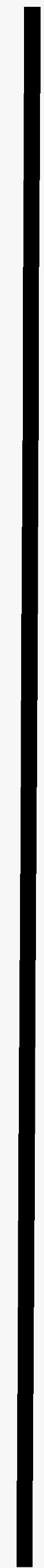


Table 9. A comparison of selected results from the base case with computations done in which the PGAS stream is not input to the gasifier.

\begin{tabular}{|lcc|}
\hline & Base & NOPGAS \\
\hline AH2OUT (kmol/s) & 0.672 & 0.672 \\
FGOXY (kmol/s) & 0.441 & 0.433 \\
AH2OUT/FGOXY & 1.52 & 1.55 \\
GQLOSS (MW) & 3.7 & 3.6 \\
SCOOLQ (MW) & 1 & 1 \\
CCOOLQ (MW) & 132.7 & 132.4 \\
ACMPQ (MW) & 3.8 & 3.7 \\
AFUELGAS - Available Energy (MW) & 9.1 & 9.1 \\
\hline
\end{tabular}

\section{Ash Removal}

In the modeled process nonreactive material, referred to here as ash whether or not it has seen any elevated temperatures, leaves the system at two places. The first is a result of classification of the incoming MSW and the other is in the fused ash stream exiting the gasifier. The ash removal in the first classification step has been somewhat arbitrarily set at $50 \%$ of the incoming ash. The amount of ash fed to the gasifier does not directly have a large impact on performance of the gasifier since the energy effects of heating the ash is relatively small. However, in this case the amount of ash may adversely effect the amount of organic material which can be fed to the gasifier in the injected slurry. This changes the fuel water ratio of the feed which has a direct bearing on gasifier performance.

In order to partially quantify the influence of the ash content on performance, a model case was run in which essentially all the ash is removed from the slurry. In a real operation a change in the ash loading may dictate a change in gasifier temperature, however this effect is not considered here and the same gasifier temperature is used in both cases. Although the details of the ash removal scheme are not directly addressed here, it is assumed that to obtain very low ash content an ash removal step after passing through the hydrothermal reactor would be necessary. Consequently, in this study case a third ash removal operation was added to the process flowsheet after the hydrothermal reactor. It was assumed that this operation remove $99 \%$ of the ash present.

In the study case the solid content of the processed slurry was assumed to be maintained at $55 \%$ percent. The result of removing the ash was to increase the slurry heating value from $11.7 \mathrm{MJ} / \mathrm{kg}$ to $14.1 \mathrm{MJ} / \mathrm{kg}$. This has a decided impact on the process efficiency. Results (Table 10) indicate the produced hydrogen to input oxygen mole ratio would be increased from 1.52 to 1.78 , a $17 \%$ improvement. Also, cooling and 
heating requirements would be reduced by more than $10 \%$. A slight increase in compressor cooling would be required because of the increase in hydrogen production.

Table 10. A comparison of selected results from the base case with computations done in which essentially all ash is removed from the processed slurry.

\begin{tabular}{|lcc|}
\hline & Base & No Ash \\
\hline AH2OUT (kmol/s) & 0.672 & 0.729 \\
FGOXY (kmol/s) & 0.441 & 0.409 \\
AHLOUT/FGOXY & 1.52 & 1.78 \\
FSTEAM (kg/s) & 2.67 & 0.47 \\
PSLURRY (kg/s) & 28.6 & 23.7 \\
& & \\
PHEATQ (MW) & 22.6 & 26 \\
PQOUT (MW) & 19.7 & 18.1 \\
GQLOSS (MW) & 3.7 & 3.5 \\
SCOOLQ (MW) & 1 & 3 \\
CCOOLQ (MW) & 132.7 & 115.6 \\
ACMPQ (MW) & 3.8 & 4.1 \\
& & \\
AFUELGAS - Available Energy (MW) & 9.1 & 10.7 \\
\hline
\end{tabular}

\section{Processed Slurry Water Content}

One of the most important variables influencing the performance of the gasifier, and thus the overall process, is the heating value of the slurry feed. The injected slurry heating value is directly proportional to the solid content of the slurry for a fixed composition of solid. The assumed base case slurry represents an optimistic estimate of the upper end of the range of solids content which could be obtained and still maintain a pumpable slurry mixture. In Table 11 the change in selected process parameters as the solid content of the slurry decreases is presented for a range of solid content of 55 to 40 weight percent solid.

As slurry heating value declines the amount of hydrogen produced decreases proportionally. At the same time the amount of oxygen required increases. This results in a decrease of performance, as measure by the produced hydrogen to injected oxygen ratio, of $14 \%$ for a drop of slurry heating value of $9.4 \%$ representing the change from the $55 \%$ solid base case to the $50 \%$ solid case. Over the range of $55 \%$ solid to $40 \%$ solid the performance drops $45 \%$ while the slurry heating value drops $27 \%$. The decline in performance relative to decline in slurry heating value is accelerated at lower slurry heating values.

Since the dilute slurries require more water to be dealt with, the heat flows into and out of the system in general also increase. In fact, the cooling required to drop out 
unwanted water prior to separating the hydrogen from other products increase $60 \%$ over the range of solid loadings assumed.

The cooling required before the second shift reactor, SCOOLQ, actually changes sign indicating that heating is needed. This is not a crucial consideration since the amount of heating is modest and it may well be that a second stage shift would be dropped or the second shift inlet would be done at a temperature below the $340 \mathrm{C}$ set in the model. For the $40 \%$ case the temperature of the gas is $304 \mathrm{C}$ prior to being heated to the set value of $340 \mathrm{C}$.

It is interesting to note that computed size of the slurry heat exchanger does not change much from case to case and in fact the area actually decreases. The slurry heat exchanger is not sensitive to the final slurry concentration since the solid content in the hydrothermal reactor is set by the requirement that the incoming raw slurry is suitably pumpable. In the base case a $6 / 1$ ratio of water to MSW is assumed and this ratio is maintained in the other study cases. The small decrease in area is a result of an increase in the amount of steam injected into the raw slurry prior to entering the hydrothermal reactor. The increased flow of slurry makes the heat exchange with the product slurry more efficient and allows a slightly smaller heat exchange area to be used. The steam injection increases because of the need for more water in the final slurry product. In the current process scheme this water is assumed to be introduced as steam to help with the final heating of the slurry to the desired reaction temperature. The increased steam input also accounts for a decrease in the heat required, PHEATQ in the hydrothermal pretreatment step. 
Table 11. A comparison of selected results from the base case with computations done in which the solid content of the processed slurry fed to the gasifier is decreased.

\begin{tabular}{|lcccc|}
\hline & Base & & & \\
\hline PSLURRY (solid wt. \%) & 55 & 50 & 45 & 40 \\
PSLURRY (Heating Value MJ/kg) & 11.7 & 10.6 & 9.6 & 8.5 \\
& & & & \\
AH2OUT (kmol/s) & 0.672 & 0.618 & 0.55 & 0.464 \\
FGOXY (kmol/s) & 0.441 & 0.471 & 0.507 & 0.553 \\
AH2OUT/FGOXY & 1.52 & 1.31 & 1.08 & 0.84 \\
FSTEAM (kg/s) & 2.67 & 5.53 & 9.03 & 13.4 \\
PSLURRY (kg/s) & 28.6 & 31.48 & 34.98 & 39.35 \\
& & & & \\
PHEATQ (MW) & 22.6 & 18.2 & 12.8 & 6 \\
PQOUT (MW) & 19.7 & 21.8 & 24.2 & 27.2 \\
GQLOSS (MW) & 3.7 & 3.9 & 4.1 & 4.4 \\
SCOOLQ (MW) & 1 & -1.2 & -3.7 & -6.9 \\
CCOOLQ (MW) & 132.7 & 156.2 & 180.9 & 211.9 \\
ACMPQ (MW) & 3.8 & 3.5 & 3.2 & 2.8 \\
& & & & \\
AFUELGAS - Available Energy (MW) & 9.1 & 7.9 & 6.7 & 5.3 \\
& & & & \\
Slurry Heat Exchanger Area (sq. m) & 3707 & 3546 & 3380 & 3207 \\
\hline
\end{tabular}

\section{Raw Slurry Water Content}

The amount of water present in the internal slurry in the hydrothermal pretreatment step will ultimately be set by several factors. A minimum water content will be imposed by the pumpability of the slurry. On the other hand, it may be that plugging and fouling of surfaces will be reduced by increasing the water levels above the minimum required. A series of cases was run to determine the impact of increasing water content of the raw slurry. The base case used a water to dry MSW ratio of 6 . This $14.3 \%$ solids loading probably represents the upper end of a pumpable raw slurry.

Since the final slurry product from the treatment was held constant and the overall decomposition of MSW was assumed not to be a function of water content, the changes in assumed raw slurry solid levels only influences results for the hydrothermal pretreatment section of the process. In Table 12 selected results for cases ranging down to a solid content of $3 \%$ in the raw slurry are given.

Since the solid content of the raw slurry directly influences the basic flow rates in the pretreatment units changes in this value directly effect most other process variables. The most striking change from a process standpoint is in the amount of water which is recycled, PRCYW1, and the size of the heat exchange surface required to recover heat 
from the reacted slurry exiting the main hydrothermal reactor. For a 3\% slurry the heat exchanger would be transferring over $600 \mathrm{MW}$ of heat energy. This is a very large unit.

Table 12. A comparison of selected results from the base case with computations done in which the water content of the raw slurry fed to the hydrothermal unit is increased.

\begin{tabular}{|c|c|c|c|c|c|}
\hline & Base & & & & \\
\hline Raw Slurry (solid wt. \%) & 14.3 & 11.0 & 8.0 & 5.0 & 3.0 \\
\hline PSLRY2 (solid wt. \%) & 13.2 & 10.8 & 7.9 & 4.9 & 2.6 \\
\hline PHEAT (solid wt. \%) & 12.0 & 9.3 & 6.9 & 4.3 & 2.6 \\
\hline PREACT (solid wt. \%) & 9.5 & 7.4 & 5.4 & 3.4 & 2.1 \\
\hline PRCYW1 (kg/s) & 135 & 182 & 259 & 428 & 727 \\
\hline PSLRY2 (kg/s) & 162 & 209 & 286 & 455 & 754 \\
\hline PHEATQ (MW) & 22.6 & 28.7 & 38.5 & 59.3 & 95.1 \\
\hline PQOUT (MW) & 19.7 & 26.4 & 36.9 & 59.6 & 98.8 \\
\hline Slurry Heat Exchanger Area (sq. m) & 3707 & 5039 & 7260 & 12266 & 21368 \\
\hline
\end{tabular}

\section{Auxiliary Fuel}

In preparing a fuel/water slurry from MSW suitable for gasification, it is probable that the amount of fuel available will be below the optimum level for the most efficient performance of the gasifier. One way to improve the overall efficiency is to add some additional fuel to the gasifier. Conceivably this could be coal added to the slurry, but added coal would probably result in a need to reduce the processed MSW content to maintain suitable pumpability, consequently the increase in fuel value of the slurry would not be large. A more attractive added fuel may be a heavy oil which has a low market value but high heating value. The heavy oil could be added to the slurry directly if it improved the solid carrying characteristics of the MSW slurry, or it could be introduced separately into the gasifier. To explore the effectiveness of adding heavy oil to the slurry prior to entering the gasifier a number of cases were run in which the auxiliary oil feedstock was increased up to a level where it represented about $20 \%$ of the total fuel value of the slurry.

The auxiliary heavy oil was assumed to have an elemental analysis of $84.44 \%$ carbon, $10.56 \%$ hydrogen, $0.49 \%$ nitrogen, $3.38 \%$ sulfur and $1.13 \%$ oxygen, all on a weight basis. The estimated heating value of this oil of $44 \mathrm{MJ}$ was obtained using the same correlation as used for the MSW related organic components. (Crude oil heating values range from $42-48 \mathrm{MJ} / \mathrm{kg} .15$ )

Table 13 list results for selected process parameters over a range of fuel input rates with the MSW slurry feed rate and composition maintained at the base case level. Over this 
range the incremental improvement in process performance remains linear with auxiliary fuel rate. That is, if a little fuel helps the overall economics of the process more fuel will also help. The limit of auxiliary fuel is reached as the $\mathrm{H}_{2} \mathrm{O}$ and $\mathrm{CO}_{2}$ become low enough so that potential endothermic reactions involving these species are inhibited. Over the range of fuel input shown in the table the levels of $\mathrm{H}_{2} \mathrm{O}$ and $\mathrm{CO}_{2}$ remain high enough so as not to be limiting.

Over the range studied hydrogen production increases over $27 \%$ while the required oxygen input increases only $12 \%$. For low cost heavy oil the increased revenue from hydrogen production would be more than twice the increased cost for the oil and oxygen. This would make the addition of auxiliary heavy oil seem an attractive process. option.

Since the oil is assumed to have more sulfur than the MSW derived components the hydrogen sulfide level of the gas exiting the gasifier would increase. Depending on the shift catalyst used this additional hydrogen sulfide may result in better catalyst performance.

Because of the general increase in hydrogen production the amount of fuel gas produced also increases with increased oil input. At the $2 \mathrm{~kg} / \mathrm{s}$ level the fuel gas would provide $60 \%$ of the direct heat required in the pretreatment area.

Increases in required cooling are modest. The primary cooling needed to drop water out of the product increases by only $7 \%$ while the hydrogen production rate is increasing $27 \%$. 
Table 13. A comparison of selected results from the base case with computations done in which varying amounts of auxiliary fuel, FFUEL, are input to the gasifier.

\begin{tabular}{|lccccc|}
\hline & Base & & & & \\
\hline FFUEL (kg/s) & 0 & 0.5 & 1.0 & 1.5 & 2 \\
AH2OUT (kmol/s) & 0.672 & 0.735 & 0.798 & 0.860 & 0.923 \\
FGOXY (kmol/s) & 0.441 & 0.455 & 0.469 & 0.482 & 0.496 \\
AH'LOUT/FGOXY & 1.52 & 1.62 & 1.70 & 1.78 & 1.86 \\
& & & & & \\
GPROD (mole \% CO2) & 20.4 & 19.7 & 19.1 & 18.5 & 18.0 \\
GPROD (mole \% H2O) & 40.7 & 39.1 & 37.5 & 36.1 & 34.7 \\
& & & & & \\
FQW2 (kg/s) & 32.3 & 33.1 & 33.9 & 34.7 & 35.5 \\
CWATER (kg/s) & 40.7 & 40.8 & 40.8 & 40.9 & 41.0 \\
& & & & & \\
CH2S (kg/s) & 0.008 & 0.013 & 0.018 & 0.024 & 0.030 \\
QGAS (mole \% H2S) & 0.03 & 0.04 & 0.05 & 0.06 & 0.07 \\
& & & & & \\
GQLOSS (MW) & 3.7 & 3.8 & 3.8 & 3.9 & 4.0 \\
SCOOLQ (MW) & 1.0 & 1.8 & 2.5 & 3.2 & 3.9 \\
CCOOLQ (MW) & 132.7 & 137.4 & 138.9 & 140.4 & 141.8 \\
ACMPQ (MW) & 3.8 & 4.1 & 4.4 & 4.8 & 5.1 \\
& & & & & \\
AFUELGAS - Available Energy (MW) & 9.1 & 10.2 & 11.2 & 12.3 & 13.5 \\
\hline
\end{tabular}

\section{Gasifier Temperature}

The gasifier temperature will be set primarily by the nature of the ash present in the slurry feed. Since the nature of the ash is not well defined it is possible that an operating temperature of the gasifier lower than the $1425 \mathrm{C}$ assumed in the base case calculations may be used. To get an idea of the sensitivity of the computed results to the assumed gasifier temperature a case was run in which a gasifier temperature $200 \mathrm{C}$ cooler was assumed. Selected results are given in Table 14.

Since the reduced temperature leads directly to a reduced sensible heat flow out of the gasifier, the performance of the system is enhanced by the reduced gasifier operating temperature. The calculations indicate an $11 \%$ increase in hydrogen production along with a 9\% drop in required oxygen would result. Also, since the amount of produced water decreases there is a drop in cooling requirements.

These estimates were made using the same gasifier parameters as defined previously. Clearly from the standpoint of optimizing hydrogen production it is advantageous to operate the gasifier at the lowest temperature consistent with proper behavior of the ash and acceptable levels of unreacted carbon in the fused ash and in the syngas. 
Table 14. A comparison of selected results from the base case with computations done in which a lower gasifier temperature is assumed.

\begin{tabular}{|lcc|}
\hline & Base \\
\hline GPROD (Temp., C) & 1425 & 1225 \\
AHLOUT (kmol/s) & 0.672 & 0.746 \\
FGOXY (kmol/s) & 0.441 & 0.399 \\
AH-2OUT/FGOXY & 1.52 & 1.87 \\
& & \\
GPROD (mole\% H2) & 19.4 & 25.1 \\
GPROD (mole \% CO) & 19.1 & 17.9 \\
GPROD (mole \% CH4) & 0.0 & 0.0 \\
GPROD (mole \% CO2) & 20.4 & 21.6 \\
GPROD (mole \% H2O) & 40.7 & 35.1 \\
& & \\
FQW2 (kg/s) & 32.3 & 26.2 \\
CWATER (kg/s) & 40.7 & 33.0 \\
& & \\
GQLOSS (MW) & 3.7 & 2.9 \\
SCOOLQ (MW) & 1.0 & 0.2 \\
CCOOLQ (MW) & 132.7 & 114.4 \\
ACMPQ (MW) & 3.8 & 4.2 \\
& & \\
AFUELGAS - Available Energy (MW) & 9.1 & 11.2 \\
\hline
\end{tabular}

\section{Coal Slurry}

In order to allow direct comparisons to be made to coal gasification performance, the ASPEN PLUS model developed here for MSW gasification was applied to a coal/water slurry feedstock with the same solid content as the MSW slurry and additionally to other coal slurries having higher solids loading. All processes downstream of the hydrothermal pretreatment step were the same for the coal cases as for the MSW base case. For the coal slurry calculations the feed rate of coal, on a dry-ash-free basis, was set equal to the dry-ash-free feed rate of the MSW slurry to the gasification unit. Two coal compositions were used, one typical of an Illinois \#6 coal and another typical of a Pittsburgh \#8 coal. The coal compositions are compared to the computed treated MSW solid in Table 15. Both coals have a higher heating value than the MSW solid because of their lower oxygen content, with the Pittsburgh \#8 representing a high grade coal. 
Table 15. Composition of coals and estimates for treated MSW slurry used in base case calculations.

\begin{tabular}{|c|c|c|c|c|c|c|c|c|}
\hline & \multicolumn{5}{|c|}{ Dry-Ash-Free Weight \% } & \multirow{2}{*}{$\begin{array}{c}\text { Atomic Ratio } \\
\text { O/C }\end{array}$} & \multirow{2}{*}{$\begin{array}{c}\text { Ash } \\
\text { (Dry wt. \%) }\end{array}$} & \multirow{2}{*}{$\begin{array}{l}\text { Heat of } \\
\text { Combustion } \\
\text { (MJ/kg) }\end{array}$} \\
\hline & C & $\mathrm{H}$ & 0 & $\mathbf{N}$ & $\mathrm{s}$ & & & \\
\hline III. \#6 Coal & 77.3 & 5.9 & 11.1 & 1.4 & 4.3 & 0.11 & 10 & 33 \\
\hline Pitt. \#8 Coal & 84.0 & 5.7 & 6.2 & 1.7 & 2.3 & 0.06 & 9.3 & 34.5 \\
\hline Treated MSW & 65.0 & 6.2 & 27.2 & 0.3 & 0.2 & 0.31 & 17.2 & 25.6 \\
\hline
\end{tabular}

The computed overall performance of the gasification and downstream processing using an MSW derived slurry is poorer than that for a gasifier fed with a coal water slurry. Results of the calculation, see Table 16, show that the computed oxygen required remains fairly constant for all cases, but the amount of hydrogen produced in the MSW base case is only about $70 \%$ of that for the $55 \%$ coal slurry case and less than $60 \%$ of that computed for the $65 \%$ Pittsburgh \#8 coal slurry. This is a direct effect of the lower heating value of the MSW slurry. The lower MSW slurry heating value results from several factors. First, the oxygen content is much higher for the treated MSW solids than for the either of the coals. Secondly, it has been assumed that the MSW solids will have a higher ash content than the coals, $17 \mathrm{wt} . \%$ compared to about $10 \mathrm{wt} . \%$ for the two coal. Finally, it is assumed that higher solids loadings are possible with coal slurries than with MSW slurries. Gas flow rates in much of the process are similar and net cooling requirements are higher for the MSW case, while the amount of hydrogen sulfide which needs to be removed is more than a factor of 10 lower for the MSW case.

Because of the similarities in flow rates downstream of the gasifier for both cases, it would appear that to a first approximation the difference in raw feedstock costs between coal and MSW must offset both the increased cost of MSW slurry preparation, compared to coal, and the decreased efficiency, as measured by hydrogen production, in order for an MSW to hydrogen process to be competitive on pure economics grounds with a more standard coal gasification processes. For the current cases, if a hydrogen selling price of $\$ 3 / \mathrm{kmol}$ is assumed then the revenue generated by hydrogen production, would be $\$ 2.02 / \mathrm{s}$ for the MSW case and as high as $\$ 3.42$ for the coal case. Now, if cost of the coal and raw MSW feedstocks are considered, coal at $\$ 30 /$ tonne and MSW tipping fee (payment for disposal) of $\$ 50 /$ tonne, the net revenue streams for the two cases become $\$ 3.52 / \mathrm{s}$ for MSW and as high as $\$ 2.99 / \mathrm{s}$ for coal. This means that about $1 / 6$ of the revenue generated by the hydrogen, $\$ 0.53 / \mathrm{s}$, is available in the MSW case to offset the increased cost of pretreatment compared to coal. For a tipping fee of . $\$ 100 /$ tonne the available revenue stream would be $\$ 1.60 / \mathrm{s}$. This revenue could support an increased capital investment between $\$ 75-225$ million (assuming a $20 \% / \mathrm{yr}$ cost of capital) for the MSW case. 
Table 16. A comparison of selected results from the base case for MSW with computations done for coal slurry feeds to the gasifier with the ash-free solid feed rate held constant.

\begin{tabular}{|lcccc|}
\hline & MSW & Coal & Coal & Coal \\
\hline PSLURRY (kg/s) & 28.62 & 26.4 & 22.3 & 22.2 \\
PSLURRY (\% solid) & 55 & 55 & 65 & 65 \\
PSLURRY (Heating Value MJ/kg) & 11.7 & 16.3 & 19.3 & 20.3 \\
& & & & \\
AH2OUT (kmol/s) & 0.672 & 0.960 & 1.011 & 1.140 \\
FGOXY (kmol/s) & 0.441 & 0.458 & 0.416 & 0.427 \\
AH2OUT/FGOXY & 1.52 & 2.10 & 2.43 & 2.67 \\
& & & & \\
GPROD (kmol/s) & 1.86 & 1.89 & 1.66 & 1.72 \\
GPROD (mole \% H2) & 19.4 & 26.2 & 29.3 & 31.5 \\
GPROD (mole \% CO) & 19.1 & 28.7 & 38.1 & 42.8 \\
GPROD (mole \% CO2) & 20.4 & 15.7 & 12.4 & 10.1 \\
GPROD (mole \% H2O) & 40.7 & 28.1 & 18.7 & 14.6 \\
GPROD (CO+H2)/FGOXY & 1.62 & 2.27 & 2.69 & 2.99 \\
& & & & \\
QASH (kg/s) & 2.88 & 1.47 & 1.47 & 1.34 \\
FQW2 (kg/s) & 32.3 & 30.6 & 26.0 & 23.3 \\
CWATER (kg/s) & 40.7 & 31.9 & 22.0 & 19.5 \\
& & & & \\
QGAS (kmol/s) & 3.65 & 3.59 & 3.10 & 3.19 \\
QGAS (mole \% H2) & 9.9 & 13.8 & 15.7 & 17.0 \\
QGAS (mole \% CO) & 9.8 & 15.1 & 20.4 & 23.2 \\
QGAS (mole \% CO2) & 10.4 & 8.3 & 6.6 & 5.5 \\
QGAS (mole \% H2O) & 69.9 & 62.2 & 56.6 & 53.8 \\
QGAS (mole \% H2S) & 0.03 & 0.47 & 0.54 & 0.29 \\
& & & & \\
GQLOSS (MW) & 3.7 & 3.7 & 3.4 & 3.5 \\
SCOOLQ (MW) & 1.0 & 6.2 & 8.6 & 10.3 \\
CCOOLQ (MW) & 132.7 & 115.2 & 87.6 & 84 \\
ACMPQ (MW) & 3.8 & 5.4 & 6.2 & 7.3 \\
AFUELGAS - Available Energy (MW) & 9.1 & 15.6 & 23.7 & 31.4 \\
\hline
\end{tabular}

\section{SUMMARY}

An ASPEN PLUS computer model of an MSW to hydrogen process has been developed to allow estimates of process performance to be computed for various possible operating conditions. The model has been used to compute a best estimate base case for a process utilizing $30 \mathrm{~kg} / \mathrm{s}$ (2600 tonne/day) of raw MSW feed. The processing scheme employed for the pretreatment of the MSW was aimed at producing a water fuel slurry 
suitable for gasification in a Texaco slurry fed gasifier. For the base case $0.672 \mathrm{kmol} / \mathrm{s}$ of hydrogen are produced (equivalent to $192 \mathrm{MW}$ of thermal energy based on hydrogen's higher heating value).

The process modeled was arranged so that all effluents from the MSW hydrothermal pretreatment are fed to the gasifier thus avoiding production of foul water and gases. The introduction of effluent gases from the pretreatment step degrades the gasifier performance since the gases have as a major constituent carbon dioxide. However, because of the relatively low flow rate it is calculated that oxygen input to the gasifier would have to be increased by less than $2 \%$, and this would lead to production of essentially the same amount of hydrogen.

Two process modifications were identified which have the potential to materially increase the process performance by increasing the gasification efficiency. One is the removal of a larger fraction of the ash (inert) material present in the MSW. If the nearly all the ash could be removed the gasifier efficiency would improve by more than $15 \%$. Also, the addition of an auxiliary feedstock, heavy oil, would increase gasifier efficiency and probably be very attractive economically.

Probably the largest potential for degradation in process efficiency from that computed for the base case would be a result of a lower solids content of the processed slurry. The base case assumes a content of 55\%, which is an optimistic guess at the upper end of that achievable. However, a reduction in solid content could be compensated for by a decrease in ash content, the presence of dissolved organic matter and the use of auxiliary liquid feedstock.

A comparison of the process using a typical coal slurry and the MSW slurry indicate that for similar gas flow rates and oxygen utilization the MSW plant would produce about $60 \%$ of the hydrogen of a coal slurry fed system. Still, with the cost of coal and tipping fees for MSW considered the amount of potential revenues for the MSW plant exceeds that of the coal plant by a considerable amount providing revenues to offset the increased cost of MSW slurry preparation compared to that of coal slurry preparation. 


\section{REFERENCES}

1. M.R. Khan, "Clean Energy from Waste and Coal". ACS Symposium Series 515. Washington, D.C: American Chemical Society, (1993).

2. Garbage - The Story of Waste Management and Recycling, (American Institute of Chemical Engineers, 345 East 47th Street, New York, N.Y. 10017), (1994).

3. Materials and Energy from Municipal Waste - Resource Recovery and recycling from Municipal Solid Waste and Beverage Container Deposit Legislation "Office of Technology Assessment (1979).

4. Solid Waste Management Technology Assessment, General Electric Company, (Van Nostrand Reinhold-General Electric Series, New York, 1975), pp 69-81.

5. Osamu Kitani and Carle W. Hall Editors, Biomass Handbook, (Gordon and Breach Science Publishers, New York, 1989), page 881.

6. Francis A. Ferraro, "Results of Emissions and Ash Testing at a Modern RefuseDerived Fuel Plant", AIChE Symposium Series, 265, Resource Recovery of Municipal Solid Wastes, Vol 84 (1993), pp 36-54.

7. Robert Rogers III, Hydrogen Production by Gasification of Municipal Solid Waste, Lawrence Livermore National Laboratory, Livermore Calif., UCRL-ID-117603 (1994).

8. Olaf A. Hougen, Kenneth M. Watson and Roland A. Ragatz, Chemical Process Principles, (John Wiley \& Sons, Inc., New York, 1954), pp 401-402.

9. N.Y. Kirov, "Specific Heats and Total Heat Contents of Coals and Related Materials at Elevated Temperatures", BCURA Monthly Bulletin, 29, (1965), page 33.

10. J.P. Schuhmachher, F.J. Huntjens and D.W. van Krevelen, "Chemical Structure and Properties of Coal XXVI - Studies on Artificial Coalifaction", Fuel 14, 223-234 (1960).

11. Michael Klosky, Norman Dickinson, and Chris Anderson, "Chlorine, Sulfur, and Soluable Slag Extraction with Energy Density Improvements of MSW Slurry", Proceedings of the 19th International Conference on Coal Utilization and Fuel Systems The Greening of Coal, Clearwater, Florida, March 21, 1994, pp 205-213.

12. Allan H. Harvey and J.M.H. Levelt Sengers, "Correlation of Aqueous Henry's Constants from $0^{\circ} \mathrm{C}$ to the Critical Point", AIChE Journal, 36, No.4 (1990), pp 539546. 
13. C.-C. Chen, H.I. Britt, J.F. Boston and L.B. Evans, "Extension and Application of the Pitzer Equation for Vapor-Liquid Equilibrium of Aqueous Electrolyte Systems with Molecular Solutes", AIChE Journal, 25 (1979), page 820.

14. S. Sircar, "Production of Hydrogen and Ammonia Synthesis Gas by Pressure Swing Adsorption", Separation Science and Technology, 25(11\&12), (1990), pp 10871099.

15. James G. Speight, The Chemistry and Technology of Petroleum, (Marcel Dekker Inc., New York, 1991), page 294. 


\begin{abstract}
APPENDIX A
The ASPEN PLUS simulator has the ability to estimate Henry's Law constants for gases based on the Extended Antoine and Brelvi-O'Connell correlations/models. These correlations do not necessarily lead to good estimates over an extended range of temperatures. A correlation proposed by Japas and Sengers 12 allows a comparison between the ASPEN PLUS built in correlations and more precise correlations tuned for nonpolar gases in aqueous systems up to the critical point of water. Henry's Law as used here relates the fugacity of a solute gas in the liquid phase to its mole fraction at infinite dilution through the relation $f=x k h$ where $f$ is the fugacity, $x$ is the mole fraction of the solute in the liquid phase and $\mathrm{kh}_{\mathrm{h}}$ is Henry's constant, which in general is a function of temperature and possibly pressure.
\end{abstract}

Table A1 compares values of Henry's constant computed from the correlation of Japas and Senger to ASPEN PLUS values. Assuming the Japas and Sengers numbers give a fair representation of Henry's constant for the three nonpolar components $\mathrm{H}_{2}, \mathrm{~N}_{2}$ and $\mathrm{CH}_{4}$ in water a few observations about the ASPEN PLUS values can be made. First, although not shown in the table, the SYSOPO option, which is the ASPEN PLUS property default option and is not setup to explicitly recognize a gas in liquid solubility, greatly over predicts the gases solubility and thus should not be used. The other ASPEN PLUS options which do recognize Henry's Law explicitly do a fair job of estimating the correct constant up to about $100 \mathrm{C}$. The ASPEN PLUS calculations begin to substantially underpredict solubility as the temperature increases. 
Table A1. Values of Henry's Law constants computed from the Japas and Sengers 12 correlation and ASPEN PLUS SYOP8A option for nonpolar species. The solvent is water.

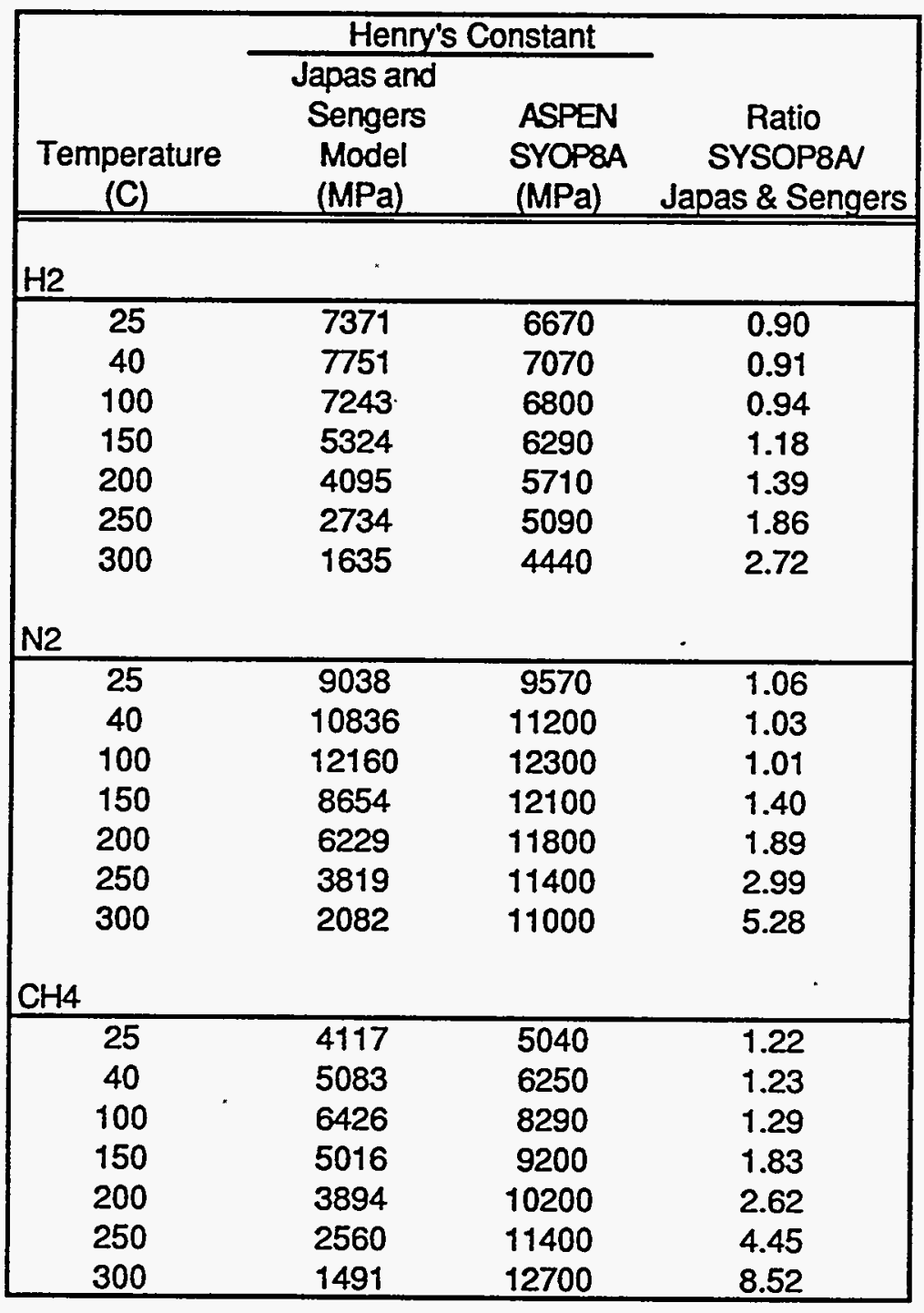

The primary gas phase component in the MSW-to-Hydrogen process, other than steam, is carbon dioxide and is not covered by the Japas and Sengers correlations because it is a polar molecule. However, earlier work by Chen et al. ${ }^{13}$ provides a Henry's Law correlation for the carbon dioxide in water (see Table A2) system up to a temperature of $220 \mathrm{C}$. Apparently, the ASPEN PLUS correlations underpredict the solubility over the entire temperature range for which the Chen et al. correlation is valid. As with the nonpolar species, the deviation seems to be greatest at high temperatures. 
Table A2. Values of Henry's Law constants computed from the Chen et al. ${ }^{13}$ correlation and ASPEN PLUS SYOP8A option for carbon dioxide. The solvent is water.

\begin{tabular}{|cccc|}
\hline & \multicolumn{2}{c}{ Henry's Constant } & \\
\cline { 2 - 3 } $\begin{array}{c}\text { Temperature } \\
\text { (C) }\end{array}$ & $\begin{array}{c}\text { Chen et al. } \\
\text { Model } \\
\text { (MPa) }\end{array}$ & $\begin{array}{c}\text { ASPEN } \\
\text { SYOP8A } \\
\text { (MPa) }\end{array}$ & $\begin{array}{c}\text { Ratio } \\
\text { SYSOP8A } \\
\text { Chen et al. }\end{array}$ \\
\hline \hline & & & \\
COe & 161 & 245 & 1.52 \\
\hline 25 & 233 & 339 & 1.45 \\
40 & 547 & 682 & 1.25 \\
100 & 678 & 1090 & 1.61 \\
150 & 647 & 1760 & 2.72 \\
200 & & 2870 & \\
250 & & 4730 & \\
300 & &
\end{tabular}




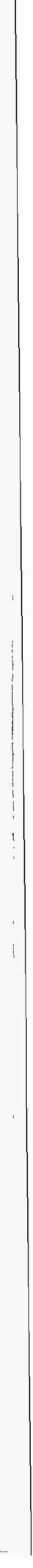




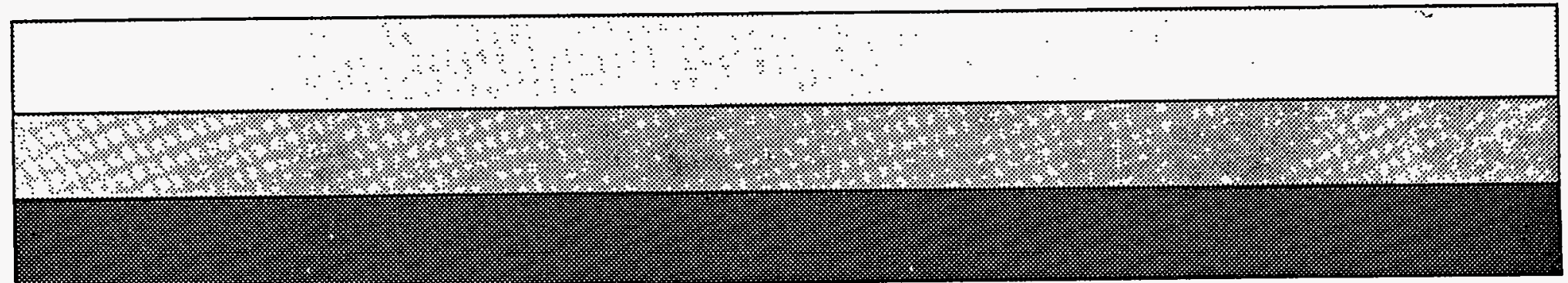

